\title{
Mouse Parabrachial Neurons Signal a Relationship between Bitter Taste and Nociceptive Stimuli
}

\author{
-Jinrong Li and $\mathbb{C}^{-C h r i s t i a n ~ H . ~ L e m o n ~}$ \\ Department of Biology, University of Oklahoma, Norman, Oklahoma 73019
}

Taste and somatosensation both mediate protective behaviors. Bitter taste guides avoidance of ingestion of toxins while pain sensations, such as noxious heat, signal adverse conditions to ward off harm. Although brain pathways for taste and somatosensation are typically studied independently, prior data suggest that they intersect, potentially reflecting their common protective role. To investigate this, we applied electrophysiologic and optogenetic techniques in anesthetized mice of both sexes to evaluate relationships between oral somatosensory and taste activity in the parabrachial nucleus $(\mathrm{PbN})$, implicated for roles in gustation and pain. Spikes were recorded from taste-active $\mathrm{PbN}$ neurons tested with oral delivery of thermal and chemesthetic stimuli, including agonists of nocisensitive transient receptor potential (TRP) ion channels on somatosensory fibers. Gustatory neurons were also tested to follow electrical pulse stimulation of an oral somatosensory region of the spinal trigeminal subnucleus caudalis $(\mathrm{Vc})$, which projects to the $\mathrm{PbN}$. Neurons composed classic taste groups, including sodium, electrolyte, appetitive, or bitter cells. Across groups, most neurons spiked to Vc pulse stimulation, implying that trigeminal projections reach $\mathrm{PbN}$ gustatory neurons. Among such cells, a subpopulation responsive to the bitter taste stimuli quinine and cycloheximide, and aversive concentrations of sodium, cofired to agonists of nocisensitive TRP channels, including capsaicin, mustard oil, and noxious heat. Such neurons populated the lateral PbN. Further, nociceptive activity in PbN bitter taste neurons was suppressed during optogenetic-assisted inhibition of the $\mathrm{Vc}$, implying convergent trigeminal input contributed to such activity. Our results reveal a novel role for $\mathrm{PbN}$ gustatory cells in cross-system signaling related to protection.

Key words: multisensory; nociception; parabrachial; somatosensory; taste; trigeminal

\section{Significance Statement}

Prior data suggest that gustatory and trigeminal neural pathways intersect and overlap in the parabrachial area. However, no study has directly examined such overlap and why it may exist. Here we found that parabrachial gustatory neurons can receive afferent projections from trigeminal nuclei and fire to oral nociceptive stimuli that excite somatosensory receptors and fibers. Activation to aversive nociceptive stimuli in gustatory cells was associated with responding to behaviorally avoided bitter tastants. We were further able to show that silencing trigeminal projections inhibited nociceptive activity in parabrachial bitter taste neurons. Our results imply that in the parabrachial area, there is predictable overlap between taste and somatosensory processing related to protective coding and that classically defined taste neurons contribute to this process.

\section{Introduction}

The mouth is richly innervated by the sensory receptors and endings of neural circuits for taste and somatosensation. Although mediating different sensory qualities, both of these modalities share the function of protective signaling against conditions as-

\footnotetext{
Received Aug. 3, 2018; revised Nov. 1, 2018; accepted Dec. 18, 2018.

Author contributions: J.L. and C.H.L. designed research; J.L. performed research; J.L. and C.H.L. analyzed data; C.H.L. wrote the paper.

This research was supported by National Institutes of Health Grant DC-011579 to C.H.L. Portions of these data were presented in abstract form at the 2016 and 2018 meetings of the Association for Chemoreception Sciences, Bonita Springs, FL. The authors thank Brad Heldmann and Jordan Norris for assistance with histology.

The authors declare no competing financial interests.

Correspondence should be addressed to Christian H. Lemon at lemon@ou.edu.

https://doi.org/10.1523/JNEUROSCI.2000-18.2018

Copyright $\odot 2019$ the authors $\quad 0270-6474 / 19 / 391631-18 \$ 15.00 / 0$
}

sociated with physiological distress. Trigeminal neurons, the primary mediators of craniofacial somatosensation, can respond to stimuli associated with tissue injury, including oral delivery of noxious heat $\left(>43^{\circ} \mathrm{C}\right.$; Zotterman, 1936; Yarmolinsky et al., 2016) and chemical agonists of transient receptor potential (TRP) ion channels involved with nociception, such as the capsaicin receptor TRP vanilloid 1 (TRPV1; Carstens et al., 1998; Caterina et al., 2000). Trigeminal neurons can also fire to oral presence of ingesta that would challenge homeostasis, such as highly concentrated salts (Carstens et al., 1998). Relatedly, receptor cells and neurons of the gustatory system mediate signals linked to protection from consumption of toxins (Scott and Mark, 1987), which can taste sour or bitter to humans (Reed and Knaapila, 2010). Moreover, the central neural processing of innately nonaversive taste stim- 
uli, such as sweeteners, can adaptively change to reflect pairing these tastes with negative ingestive consequences (Chang and Scott, 1984; Grossman et al., 2008).

In addition to overlapping function, neural pathways for taste and somatosensation physically overlap and intersect at multiple levels of the nervous system, including early stages of the neuraxis. The lingual branch of the trigeminal nerve partly innervates tongue tissue containing taste buds innervated by the chorda tympani (CT) nerve, a major taste-active facial nerve afferent (Abe et al., 2005; Dhaka et al., 2008). Excitation of the lingual nerve can modulate gustatory firing in neurons of the CT and also the nucleus of the solitary tract (NTS), the first central relay for taste, potentially through axonal reflex release of peripheral neuromodulators (Wang et al., 1995; Simons et al., 2003a). Moreover, although most trigeminal fibers enter the brain to project to the hindbrain trigeminal sensory complex (Marfurt and Rajchert, 1991), some reach CT-supplied neurons in the NTS (Felizardo et al., 2009). Accordingly, electrical stimulation of mandibular trigeminal afferents can excite and modify sensory firing in taste-active NTS neurons (Boucher et al., 2003; Braud et al., 2012; Li and Lemon, 2015b).

While the function of physiological ties between taste and somatosensory circuits is unknown, such phenomena could reflect the common role of both systems in protective coding. In rodents, data relevant to this question stem from studies on the parabrachial nucleus $(\mathrm{PbN})$ of the pons, which is implicated for affective processing in gustation (Yamamoto et al., 1994) and pain (Gauriau and Bernard, 2002). Central tract tracing work revealed that the dorsal spinal trigeminal subnucleus caudalis $(\mathrm{Vc})$, which is involved in part with oral nociceptive processing (Carstens et al., 1998), projects to regions of the $\mathrm{PbN}$ containing gustatory-responsive neurons, implying that $\mathrm{PbN}$ circuits support the convergence of trigeminal sensory signals with taste (Cechetto et al., 1985). Further, independent functional studies on gustation or nociception identified that the oral delivery of bitter tastants (Yamamoto et al., 1994; Halsell and Travers, 1997; Geran and Travers, 2009) and noxious stimulation, including heat or pinch, of trigeminal receptive fields (Bernard and Besson, 1990; Campos et al., 2018) excites neurons in common PbN subregions, including the external lateral and external medial $\mathrm{PbN}$ subnuclei. The above data open the possibility that aversive somatosensory and gustatory signals could activate the same $\mathrm{PbN}$ neurons.

To test this idea, we made in vivo electrophysiological recordings from gustatory-active $\mathrm{PbN}$ neurons stimulated with oral thermal and chemesthetic stimuli associated with somatosensory and pain transmission. Electrical and optogenetic perturbation directed to $\mathrm{Vc}$ axonal projections to the $\mathrm{PbN}$ evaluated connectivity of taste-active $\mathrm{PbN}$ cells with upstream trigeminal circuits. Our results provide evidence that ascending trigeminal projections reach multiple types of taste-identified neurons in the $\mathrm{PbN}$ and specifically imbue a subpopulation of bitter taste-responsive cells with sensitivity to oral nociceptive stimuli. Such "gustatory" neurons appear to convey signals relevant to protective coding in dual systems and to mediate functions beyond unimodal taste.

\section{Materials and Methods}

\section{Animals and preparation}

These studies used adult mice of both sexes from the C57BL/6J (B6) line (stock \#000664, The Jackson Laboratory) and mice derived from a cross between $\mathrm{B} 6$ mice and a mouse line that affords optogenetic control of neural inhibition, discussed below. All mice were naive to experimentation and were housed in a vivarium that maintained a $12 \mathrm{~h}$ light/dark cycle and an air temperature of $\sim 20^{\circ} \mathrm{C}$. Food and water were available ad libitum.

In brief, the procedures described below allowed for acute recording of extracellular spikes from taste-active $\mathrm{PbN}$ neurons in anesthetized mice during controlled stimulation of the oral cavity with gustatory and somatosensory stimuli. We also tested whether the recorded $\mathrm{PbN}$ units fired spikes in response to weak electrical pulses delivered through the tip of a stimulation electrode located in the orosensory Vc, thus evaluating functional coupling of central trigeminal circuits with gustatory cells. In a second set of experiments that involved optogenetic-assisted neural inhibition, a fiber optic probe was positioned alongside the Vc stimulation electrode to enable tests on how reversible light-induced suppression of trigeminal circuits impacted somatosensory firing in taste-active $\mathrm{PbN}$ cells.

Mice were prepared for neurophysiologic and optogenetic experiments with guidance from the University of Oklahoma Institutional Animal Care and Use Committee, which reviewed and approved our procedures, and the National Institutes of Health. To ease the injection of a short-acting anesthetic/analgesic agent needed for initial preparation, mice were briefly placed in a small Plexiglas box infused with $4-5 \%$ isoflurane in oxygen until breathing was regularly slow and body movement was absent. Mice were then inducted using a mixture of ketamine (100 mg/kg, i.p.) and xylazine (10 mg/kg, i.p.). Atropine ( $24 \mu \mathrm{g} / \mathrm{kg}$, i.p.) was also administered to reduce bronchial secretions. Once anesthetized, as evidenced by the absence of a reflex response, a tracheostomy tube (polyethylene 60; length, $25 \mathrm{~mm}$ ) was inserted to allow breathing during oral stimulation with liquids. To facilitate access to the oral cavity, as discussed below, a small suture was placed through the superficial rostroventral tongue and the mandibular incisors were partly trimmed using rongeurs. Mice were then secured in a stereotaxic instrument with ear bars (model 930, David Kopf Instruments). For the long-duration anesthesia needed for recording studies, the open end of the tracheostomy tube was coupled to concentric pressure-vacuum gas exchange tubing (Wilson and Lemon, 2014), through which mice freely inhaled $0.8-1.2 \%$ isoflurane in oxygen. Under this system, mice respired anesthetic gas without the aid of an external ventilator. Body temperature was kept at $\sim 37.4^{\circ} \mathrm{C}$ by a feedback-controlled heating pad.

Anesthesia was monitored and confirmed by the absence of a reflex to heavy pinch applied to a hindpaw. Under anesthesia, the scalp was incised along the midline of the skull to expose bregma and lambda, which were brought into the same dorsoventral plane through stereotaxic adjustments. The mandible was gently deflected downward and held in position by a small thread of surgical silk that passed caudal of the incisors and was fixed to the stereotaxic device. The tongue was extended from the mouth by light pressure on the rostroventral suture. To allow electrode access to the $\mathrm{PbN}$, a unilateral craniotomy removed a small portion of the interparietal bone and exposed the surface of the inferior colliculus and the parts of the cerebellum. To allow electrode and fiber optic access to the $\mathrm{Vc}$, the caudal zone of the occipital bone ipsilateral to the targeted $\mathrm{PbN}$ was trimmed. Dura mater overlying the inferior colliculus and the targeted region of the medulla was retracted to facilitate electrode passage into brain tissue.

A concentric bipolar stimulation electrode (model CEA-200, Microprobes) was targeted to the Vc using a micromanipulator (model SM15R, Narishige International) attached to the stereotaxic device. For optogenetic studies involving light-induced neural suppression also directed to the Vc, the cut and prepared end of a 200- $\mu \mathrm{m}$-diameter fiber optic cable (0.39 numerical aperture; ThorLabs) was coupled alongside the Vc stimulation electrode, with the tip of the fiber optic positioned just behind the electrode tip to enable light delivery to the brain area penetrated by the electrode. Coordinates for the stimulation electrode targeted the oral thermal/sensory $\mathrm{Vc}$ in mice, as based on our prior work (Lemon et al., 2016), as follows: $\sim 8.0-8.2 \mathrm{~mm}$ caudal of bregma; $\sim 1.8-$ $2.2 \mathrm{~mm}$ lateral of the midline; and superficial depth just below the medullary surface. The stimulation electrode approached the $V_{c}$ at an $\sim 15^{\circ}$ angle in the sagittal plane to allow space for $\mathrm{PbN}$ access. Final positioning of the stimulating electrode was confirmed by electrophysiological monitoring for the first signs of multiunit activity to oral presentation of cool water following $35^{\circ} \mathrm{C}$ adaptation, as below. Once in position, the core and 
outer leads of the stimulating electrode were electrically connected to, respectively, the positive and negative poles of a constant current stimulus isolation unit (model PSIU6X, Grass Technologies) coupled to a programmable square pulse stimulator (S88X, Grass Technologies).

Following positioning of the Vc stimulation electrode, the tip of the recording electrode (custom 2-5 M $\Omega$ single-channel tungsten probe, FHC) was targeted to the $\mathrm{PbN}$ using stereotaxic coordinates: $4.7-5.0 \mathrm{~mm}$ caudal of bregma, $1.2-1.5 \mathrm{~mm}$ lateral of the midline, and $2.3-3.0 \mathrm{~mm}$ below the brain surface. The dorsoventral position of this probe was stepped by an electronic micropositioner (model 2660, David Kopf Instruments). While lowering the electrode, taste-sensitive neurons were sought out and identified through monitoring for excitatory single-unit activity to $300 \mathrm{~mm} \mathrm{NaCl}$, which interspersed continued oral delivery of $35^{\circ} \mathrm{C}$ water as below. Electrophysiological activity was AC amplified (P511 with high-impedance probe, Grass Technologies), bandpass filtered $(\sim 0.3-10 \mathrm{kHz})$, and monitored on an oscilloscope and loudspeaker. Well isolated single-neuron spikes were sampled $(25 \mathrm{kHz})$ under a template-matching algorithm (1401 interface and Spike2 software version 9, CED). Time stamps for spikes were captured with a precision of $0.1 \mathrm{~ms}$. Data files for individual trials were downloaded to storage media while recording and analyses were performed off-line.

\section{Electrical stimulation of the $V c$}

To investigate their potential upstream coupling with trigeminal circuits, taste-sensitive $\mathrm{PbN}$ neurons were tested for spike activation following delivery of a train of electrical pulses to the ipsilateral Vc at $1 \mathrm{~Hz}$ (pulse amplitude, $\sim 150 \mu \mathrm{A}$; pulse width, $500 \mu \mathrm{s}$ ). Each pulse was considered to mark a trial, with the $100 \mathrm{~ms}$ period before the pulse referenced as baseline/random firing. Over many trials, spikes that arose within a $200 \mathrm{~ms}$ postpulse window were statistically compared with baseline activity to determine whether the unit reliably spiked in response to electrical stimulation of the $\mathrm{Vc}(\mathrm{V}+$ neuron $)$, as below. Note that this procedure did not intend to reveal the number of synapses involved but evaluated electrophysiologic coupling between the stimulated brain site and recorded $\mathrm{PbN}$ neurons.

\section{Oral stimuli}

$\mathrm{PbN}$ neurons identified to respond to taste input were tested for sensitivity to the oral presence of solutions of diverse gustatory chemicals, thermal stimuli in the form of temperature-adjusted volumes of purified water, and solutions of chemesthetic stimuli including capsaicin. Capsaicin was applied to lingual tissue in a unique manner, as discussed below. All other stimuli were stored in airtight glass bottles and thermally controlled by submersion in microprocessor-regulated warming and recirculated cooling/heating water baths. Temperature-controlled stimulus solutions were flowed into the mouse oral cavity on individual trials using a custom apparatus operated and timed by the data acquisition system, as in our prior studies (Wilson and Lemon, 2014; Lemon et al., 2016). Briefly, on a given trial, a three-way valve seamlessly switched oral solution flow from a $35^{\circ} \mathrm{C}$ (i.e., near physiological temperature) purified water adaptation rinse to a stimulus solution delivered for a brief period, following which flow returned to the $35^{\circ} \mathrm{C}$ adaptation rinse. The adaptation rinse continued between trials to facilitate the thermal adaptation of oral tissue to a physiological level. Intertrial intervals were $\sim 2 \mathrm{~min}$. Solutions flowed into the mouth at a rate of $\sim 1.5 \mathrm{ml} / \mathrm{s}$ and bathed anterior and posterior oral fields (i.e., whole-mouth stimulation; Wilson et al., 2012).

Stimuli were loaded into the delivery system by funnel, with effort made to take about the same amount of time to prepare and start each trial for thermal consistency. As in our prior work (Lemon et al., 2016), solution flow temperature was continuously monitored at the moment of oral entry using a small thermocouple probe (time constant, $0.005 \mathrm{~s}$; IT-1E, Physitemp Instruments) connected to a digital thermometer (precision, $0.1^{\circ} \mathrm{C}$; BAT-12, Physitemp Instruments). The analog output of the thermometer was sampled $(1 \mathrm{kHz})$ by the data acquisition system to give real-time measurement of the temperature of oral solution flow alongside cellular spiking data. Stimulus temperatures stated herein were quantified as mean oral temperature across trials during the last $3 \mathrm{~s}$ of stimulus delivery. In between trials, the funnel and all stimulus passages of the delivery system were rinsed with $35^{\circ} \mathrm{C}$ purified water.
Taste, thermal, and chemesthetic stimuli were respectively tested in three separate blocks. Taste stimuli were $500 \mathrm{~mm}$ sucrose (SUC), a mixture of $100 \mathrm{~mm}$ monopotassium glutamate and $10 \mathrm{~mm}$ inosine 5'monophophate (UMA), $100 \mathrm{~mm} \mathrm{NaCl}$ (NAC), $10 \mathrm{~mm}$ citric acid (CIT), $10 \mathrm{~mm}$ quinine-HCl (QUI), and $0.1 \mathrm{~mm}$ cycloheximide (CHX). These stimuli are associated with the sweet (SUC), umami (UMA), salty (NAC), sour (CIT), and bitter (QUI and CHX) human taste categories. Stimulus concentrations were selected from prior gustatory electrophysiology studies conducted in mouse brainstem (Wilson et al., 2012; Tokita and Boughter, 2016). Notably, the bitters QUI and CHX induce strong oral sensory aversion in naive B6 mice (Boughter et al., 2005; Ellingson et al., 2009). Central gustatory neuronal activation to cycloheximide is a frequent marker of taste neurons that are strongly responsive to diverse bitter taste stimuli, including quinine (Geran and Travers, 2006, 2009; Wilson et al., 2012). On the other hand, quinine more broadly stimulates bitter-selective and other types of gustatory neurons, including cells that fire strongly to electrolytes (Geran and Travers, 2009; Wilson et al., 2012). Taste chemicals were of high purity (purchased from SigmaAldrich) and dissolved in purified water. Taste solutions were delivered for $5 \mathrm{~s}$ at an oral temperature of $28^{\circ} \mathrm{C}$. The ordering of taste chemical trials was generally randomized, without replacement, for each cell.

Thermal stimuli were $5 \mathrm{~s}$ presentations of purified water adjusted to each of five temperatures, as measured inside the mouth, as follows: $14^{\circ} \mathrm{C}, 21^{\circ} \mathrm{C}, 28^{\circ} \mathrm{C}, 35^{\circ} \mathrm{C}$, and $48^{\circ} \mathrm{C}$. These temperatures included noxious heat $\left[48^{\circ} \mathrm{C}\right.$ (abbreviated as HEAT) $]$ and spanned a broad range of distinct cooling and warming values that can excite oral trigeminal neurons (Carstens et al., 1998; Lemon et al., 2016). Note temperatures below physiological value $\left(35^{\circ} \mathrm{C}\right)$ were considered "cool." Thermal trial order was randomized.

Finally, the chemesthetic stimuli tested were $28^{\circ} \mathrm{C} 1.28 \mathrm{~mm} \mathrm{~L}$-menthol (MENT), $35^{\circ} \mathrm{C} 1 \mathrm{~mm}$ allyl isothiocyanate [AITC (mustard oil)], and room temperature $1 \mathrm{~mm}$ capsaicin (CAP). Capsaicin is an agonist of TRPV1 expressed by somatosensory neurons (Caterina et al., 1997); mustard oil stimulates TRP ankyrin 1 (TRPAl; Jordt et al., 2004) and partly TRPV1 (Everaerts et al., 2011); menthol is associated with activation of TRP melastatin 8 (TRPM8; McKemy et al., 2002). Wild-type and B6 mice show strong ingestive and oral sensory avoidance of CAP and AITC (Ellingson et al., 2009; Everaerts et al., 2011). In B6 mice, $1.28 \mathrm{mM}$ MENT can electrophysiologically excite trigeminal ganglion neurons when delivered orally but cause only relatively mild avoidance in briefaccess drinking tests (our unpublished observations). MENT and AITC were dissolved in purified water. CAP was dissolved in a vehicle of $1.5 \%$ ethanol/1.5\% Tween 80 in purified water; $\mathrm{PbN}$ neurons were also tested with the CAP vehicle on a separate trial. Solutions of MENT and AITC were presented orally for $10 \mathrm{~s}$ using our stimulus delivery system. For CAP and CAP vehicle trials, a small volume (estimation, $150 \mu \mathrm{l}$ ) of the solution was applied to a cotton-tipped applicator that was lightly dabbed onto the exposed rostral-ipsilateral tongue for $20 \mathrm{~s}$; during this period, the delivery of the oral adaptation rinse was paused. Postmortem inspection of a mouse tongue where thionin dye was applied in the same manner revealed that stimuli dabbed by cotton swab were restricted to tongue regions rostral of the median eminence and did not reach caudal foliate or circumvallate taste papillae. While the order of MENT and AITC trials varied across cells, the CAP trial was always tested after the CAP vehicle, at the end of the chemesthetic stimulus block, as CAP delivery induced lingering responses and effects (see also Carstens et al., 1998).

If the $\mathrm{PbN}$ neuron remained isolated and displayed baseline firing $\sim 20$ min after completion of the CAP trial, it was tested with a half-log step concentration series of $\mathrm{NaCl}$ that included 10, 30, 100,300, and $1000 \mathrm{~mm}$ solutions presented at $28^{\circ} \mathrm{C}$. This series included high concentrations of $\mathrm{NaCl}(300$ and $1000 \mathrm{~mm}$ ) that can elicit intake avoidance in B6 mice (Ninomiya et al., 1989; Eylam and Spector, 2002). The testing order for $\mathrm{NaCl}$ concentrations was randomized for each cell.

\section{Optogenetic-assisted suppression of Vc oral activity during} $\mathrm{PbN}$ recordings

In a second experiment, optogenetics was used to reversibly inhibit $\mathrm{Vc}$ circuitry during recordings from $\mathrm{PbN}$ neurons that reliably spiked to $\mathrm{Vc}$ 
pulse stimulation to evaluate how temporary removal of ascending trigeminal input affected $\mathrm{PbN}$ firing over multiple trials to the bitter tastant QUI and nociceptive stimulus HEAT. For these tests, we targeted $\mathrm{V}^{+}$ $\mathrm{PbN}$ cells sensitive to both QUI and HEAT and partly used stereotaxic coordinates to acquire such neurons from the lateral $\mathrm{PbN}$, as recording and histological results that emerged during the first study implicated this area as supporting neural cosensitivity to bitter taste and nociceptive stimuli. HEAT was used as a nociceptive stimulus because it induced activity in $\mathrm{PbN}$ neurons that readily reverted to baseline on stimulus cessation, which avoided lasting neural excitation and carryover effects that could result from the application of a chemonociceptive stimulus, such as CAP. We used a strategy of silencing by excitation (Wiegert et al., 2017), where the natural inhibitory circuitry of the Vc was acutely engaged by light to suppress activity in an oral sensory-verified region of this nucleus. The Vc is heavily populated with inhibition-associated $\mathrm{GABA}^{+}$cells (Ginestal and Matute, 1993) that do not project to the $\mathrm{PbN}$ (Haring et al., 1990) and likely modulate intra-Vc processing and Vc outputs. The location of oral sensory neurons in the superficial dorsal Vc (Carstens et al., 1998; Lemon et al., 2016) eased light delivery to this circuit.

Mice used for optogenetic studies were bred from a cross between wild-type B6 mice and hemizygous VGAT-ChR2-EYFP BAC line 8 mice (stock \#014548, The Jackson Laboratory; Zhao et al., 2011). The latter express the excitatory opsin channelrhodopsin-2 (ChR2) and an enhanced yellow fluorescent protein (EYFP) tag in neurons containing the vesicular GABA transporter (VGAT). VGAT is found in GABAergic cells implicated for inhibition (Sagné et al., 1997). VGAT-ChR2-EYFP mice afford reversible photoinhibition of small volumes of neural tissue through selective activation of local inhibitory interneurons with blue light (Guo et al., 2014; Sofroniew et al., 2015; Wiegert et al., 2017). The offspring of our cross were identified as $\mathrm{ChR} 2{ }^{+}$(VGAT-ChR2 mice) or $\mathrm{ChR} 2^{-}$by the presence or absence, respectively, on postnatal day $0-2$ of transdermal EYFP illumination in $\mathrm{VGAT}^{+}$spinal cord interneurons (MZ10 F stereomicroscope with EYFP fluorescence, Leica Microsystems). VGAT-ChR2 mice were also confirmed as positive for ChR2 during setup for electrophysiological testing by monitoring for change in $\mathrm{Vc}$ unit activity following blue laser pulse stimulation of the $\mathrm{Vc}$, as shown below. For some of these mice, EYFP fluorescence of brain tissue was assessed and verified following perfusion at the end of $\mathrm{PbN}$ unit recordings. EYFP fluorescence was expectedly absent from the brains of all littermate $\mathrm{ChR} 2{ }^{-}$mice, which were used as controls for nonspecific effects of illumination of brain tissue.

Blue laser light ( $473 \pm 1 \mathrm{~nm}$; DPSS laser, OEM Laser Systems) was delivered to superficial medullary tissues through the fiber optic that was paired, as above, to the electrical stimulation electrode, which targeted oral sensory Vc circuitry. Light irradiance $\left(50-70 \mathrm{~mW} / \mathrm{mm}^{2}\right.$ at fiber tip) enabled activation of $\mathrm{ChR} 2{ }^{+}$inhibitory circuits influencing oral sensory medullary trigeminal and $\mathrm{Vc}$ neurons, as below. For test trials, stimulusinduced spike activity was repeatedly recorded from a $\mathrm{Vc}$-coupled $\mathrm{PbN}$ neuron during oral presentation of the stimulus in unison with blue light delivery to the $\mathrm{Vc}$ (Vc laser trials) or without laser delivery (control trials). Trials were sequenced and analyzed as below. On Vc laser trials, light delivery was turned on and off at the beginning and end, respectively, of the oral stimulus period using transistor-transistor-logic modulation controlled by the data acquisition system. With the exception of one cell where responses on QUI trials were quantified over a $5 \mathrm{~s}$ stimulus window due to an extended response latency, stimulus periods were shortened to $2 \mathrm{~s}$ in optogenetic experiments to accommodate the intent to test single $\mathrm{PbN}$ cells with many Vc laser/control trials, as below, and to reduce oral tissue exposure to noxious heat.

\section{Histology}

After data were acquired from the final $\mathrm{PbN}$ neuron of the day, mice were overdosed with sodium pentobarbital ( $\geq 130 \mathrm{mg} / \mathrm{kg}$, i.p.) and weak current $(100 \mu \mathrm{A} / 1.5 \mathrm{~s})$ was passed through the recording electrode tip to mark its last position. Mice were transcardially perfused with isotonic saline followed by $4 \%$ paraformaldehyde $/ 3 \%$ sucrose. Brains were removed and stored in a $4 \%$ paraformaldehyde $/ 20 \%$ sucrose solution. Coronal sections $(40 \mu \mathrm{m})$ from each brain were mounted onto slides and stained for histological analysis of electrode placement using anatomical landmarks (Franklin and Paxinos, 2008). Note that a majority of, but not all, recording sites were marked or recoverable.

\section{Experimental design and statistical analysis}

Electrophysiological recording and stimulation studies on B6 mice. This experiment involved mice of both sexes, using 25 male (mean \pm SD body weight, $27.0 \pm 2.8 \mathrm{~g}) 29$ female $(22.0 \pm 1.8 \mathrm{~g})$ animals. From these mice, 73 taste-active $\mathrm{PbN}$ neurons were recorded and tested for electrophysiologic coupling with the Vc. Evidence for or against Vc coupling could not be determined for six cells and one additional neuron did not cluster with the major neural groups defined below; these seven cells were discarded from further analyses. Overall, gustatory response data were analyzed from $66 \mathrm{PbN}$ neurons, albeit only subsets of these cells could be held across the remaining stimulus conditions and trial blocks; cell numbers used for specific analyses are denoted in the Results section and figure captions. Sample sizes were comparable to those in the authors' prior neurophysiological studies on taste and trigeminal processing in mice (Li and Lemon, 2015a; Lemon et al., 2016). Somatosensory-specific $\mathrm{PbN}$ neurons were encountered in our recordings but were not included in analyses due to the focus on only taste-active cells.

A two-way sex $\times$ stimulus ANOVA applied to firing to taste stimuli in hertz, calculated as below, by $\mathrm{PbN}$ neurons acquired from female (34 cells) and male (32 cells) B6 mice revealed a nonsignificant main effect of $\operatorname{sex}\left(F_{(1,64)}=0.3, p=0.6\right)$ and nonsignificant sex $\times$ stimulus interaction $\left(F_{(5,320)}=1.96, p=0.09\right)$. Thus, sex was not included as a factor in subsequent analyses. Among analyzed neurons, 32 individual and 17 pairs of $\mathrm{PbN}$ units were recorded from separate $\mathrm{B} 6$ mice. Pairs of neurons were always recorded in sequence, not simultaneously, with the second cell of the pair acquired after repositioning of the $\mathrm{PbN}$ recording electrode. Across cells sampled as pairs, no significant correlations were noted between their responses to SUC, UMA, NAC, CIT, QUI, or CHX $(-0.17<$ Spearman's rank correlation coefficient $<0.23, p>0.4)$, implying that these neurons displayed statistical independence in their firing characteristics.

Analysis of electrophysiologic coupling between the Vc and PbN neurons. A statistical method was used to evaluate whether $\mathrm{PbN}$ neurons reliably generated spikes in response to electrical pulse stimulation directed to the Vc. For Vc stimulation trials (generally, 40 were tested) acquired from an individual neuron, time stamps for spikes that followed the electrical pulse (time $=0 \mathrm{~ms}$ ) were conflated into a single vector. An iterative Poisson-based method (Chase and Young, 2007; Wilson and Lemon, 2014) estimated the probability that a spike density built over sequential spikes in this vector was similar to periods of random firing. A resultant low probability suggested that spikes followed $\mathrm{Vc}_{\mathrm{c}}$ stimulation at a rate greater than expected by chance. The time of the evoked spike where this probability became $<10^{-6}$ was taken as the latency of the neuron to fire to Vc stimulation. If this latency was $<100 \mathrm{~ms}$ (i.e., within $100 \mathrm{~ms}$ of the Vc pulse), the neuron was classified as receiving electrophysiologic input from the $\mathrm{Vc}\left(\mathrm{V}^{+}\right.$neuron $)$. Otherwise, the cell was considered uncoupled with the $\mathrm{Vc}\left(\mathrm{V}^{-}\right.$neuron$)$.

To ensure that the classification of neurons as $\mathrm{V}^{-}$did not result from the failure of the electrical stimulation setup, all $\mathrm{V}^{-}$cells included in analyses were acquired from mice where electrical pulse stimulation of the $\mathrm{Vc}$ could induce spikes in other PbN neurons. Further, to control for nonspecific activation, in two mice the electrical stimulation probe was repositioned to locations medial of the $\mathrm{Vc}$ and just across the midline (superficial depth) to determine whether pulse stimulation directed to non- $\mathrm{Vc}$ tissue could evoke spikes in the recorded $\mathrm{PbN}$ neurons. However, in these cases evoked spikes disappeared in $\mathrm{PbN}$ units, only to reappear with probe repositioning and pulse stimulation of tissue at the lateral coordinate for the $\mathrm{Vc}$.

Measurement of stimulus activity. With the exception of the CAP trials discussed below, all stimulus responses by $\mathrm{PbN}$ cells were quantified as the firing rate during the stimulus period, expressed as spikes per second or hertz, corrected for the baseline firing rate. In these cases, the spike rate during the prestimulus period of a trial was subtracted from the firing rate measured during stimulus delivery. For analysis purposes, the stimulus period was considered to lag by $250 \mathrm{~ms}$ from the computer-initiated 
signal for stimulus onset to accommodate transitions between oral adaptation rinse and stimulus flows.

Activity to CAP was also expressed in hertz but was computed differently due to the unique delivery method for this stimulus and atypical time course of CAP-evoked responses, which could arise with a delay and continue during the poststimulus rinse period for an extended length of time. Thus, firing on CAP trials was quantified based on a $20 \mathrm{~s}$ window that began $10 \mathrm{~s}$ before the termination of CAP delivery and ended $10 \mathrm{~s}$ after this mark. This same window was used to quantify neural firing rates during application of the CAP vehicle, which was the control, or baseline, condition for CAP activity. To compute the corrected CAP response for each cell, the spike rate on the vehicle trial was subtracted from the firing rate computed on the CAP trial.

For some analyses, stimulus responses by individual $\mathrm{PbN}$ neurons were converted to standardized firing. For a given neuron, the corrected firing rate computed on each trial was divided by the SD of firing by this cell across all trials considered. This metric was unitless and facilitated analyses of patterns of cross-modal activity with different time course and comparisons among cells that sometimes displayed different general firing rates (Lemon et al., 2016).

Determination of gustatory neural groups. To group cells by taste sensitivity, hierarchical cluster analysis was applied to a distance matrix for all $\mathrm{PbN}$ neurons, where pairwise neural distance was computed as 1 minus the linear correlation between firing in hertz to SUC, UMA, NAC, CIT, QUI, and CHX. Amalgamation proceeded under the average linkage method. This approach has been extensively used to group and classify gustatory neurons, including those in the $\mathrm{PbN}$ (Geran and Travers, 2009; Tokita and Boughter, 2016). Identification of a marked break, or "elbow," in a line plot of cluster distance against amalgamation steps (i.e., a scree plot) revealed the number of neural groups present in the cluster solution (Lemon et al., 2016). The average firing to taste stimuli by neurons composing each group was used to define gustatory cellular types.

Analysis of $\mathrm{NaCl}$ concentration response data. Factorial ANOVA was applied to analyze spike firing in hertz to the $\mathrm{NaCl}$ concentration series (repeated measure) across gustatory neural groups (between factor). Mauchly's test evaluated the sphericity assumption associated with repeated measurements. Violation of this assumption led to correction of $F$-value degrees of freedom using the Greenhouse-Geisser procedure; corrected degrees of freedom are reported herein as real numbers, where applicable. Following a significant group $\times$ concentration interaction, a trend analysis was conducted on the simple effect of concentration for each neural group using linear (first-order), quadratic (second-order), and cubic (third-order) polynomial contrasts to evaluate the form of the relationship between cellular activity and ascending $\mathrm{NaCl}$ concentration steps. In each case, the highest-order polynomial fit that was found to be significant was selected as a group's trend in responding to $\mathrm{NaCl}$ over the concentration range. Inspection of these trends gauged neuronal selectivity across $\mathrm{NaCl}$ concentrations. For contrast analyses, the error term for each $F$ test was calculated from responses by only the cells under consideration due to differences in response variance across groups.

Also for grouped neurons, doubly logarithmic linear regression was applied to their firing in hertz over elevated concentrations of $\mathrm{NaCl}(100$, 300 , and $1000 \mathrm{~mm}$ ). By using log-log coordinates, the slope of the regression line reflected the change in firing with concentration on a percentage basis and, thus, indexed neuronal sensitivity to high $\mathrm{NaCl}$. A $t$ test with $\mathrm{df}=n-2$ evaluated deviation of the regression line slope from 0 . Due to the use of logarithmic scales, a value of 1 was added to each response included in this analysis to accommodate a small fraction of just below zero firing rates to $\mathrm{NaCl}$ (Wilson and Lemon, 2014).

Multidimensional scaling analysis. The organization of responses by $\mathrm{PbN}$ gustatory neurons to taste, thermal, and chemesthetic stimuli was visualized using multidimensional scaling (MDS) analysis, which generated a spatial representation of associations among these responses. The analysis placed stimuli that induced similar patterns of activity across neurons close together in a coordinate space, whereas those with dissimilar patterns were situated apart. MDS analysis was applied to a matrix of correlation distances $(1-$ Spearman's rank correlation coefficient) among stimuli computed using response rates, in hertz, by $\mathrm{V}^{+}$and $\mathrm{V}^{-}$ neurons that completed testing with the three stimulus blocks. A three- dimensional MDS solution was found to notably reduce stress (i.e., the badness of fit of the MDS reduction to the data) as opposed to a twodimensional solution, albeit a further substantial drop in stress was not observed with four dimensions. Thus, three dimensions were used for the final MDS analysis and visualization. To avoid local minima, threedimensional MDS was repeated 50 times with random starting configurations and the iteration that showed the least stress used for plotting.

Multiple regression analysis. A multiple regression approach was used to explore correlations among activity to nociceptive and bitter taste stimuli in $\mathrm{V}^{+} \mathrm{PbN}$ gustatory cells, using nociceptive firing as the dependent measure. Unique correlations between firing to specific nociceptive and bitter stimuli were indexed using semipartial correlation coefficients $(s r)$, which can account for redundancies among independent variables (Tabachnick and Fidell, 2001). Regression analyses were performed on standardized firing. To mitigate data heteroscedasticity, weighted regressions were used, where cells with less predictive error for nociceptive firing were, in general, given more weight in the analysis. To compute regression weights, cellular responses to a nociceptive stimulus were first regressed onto firing to bitter stimuli. The absolute values of the residuals from this regression were then regressed onto bitter activity, with, for each neuron, the reciprocal of its resultant squared predicted value taken as its regression weight. Data were inspected for multivariate outliers, but none were detected based on calculations of Mahalanobis distance, distributed as $\chi^{2}$ with $\mathrm{df}=2$ and using $\alpha=0.001$ (Tabachnick and Fidell, 2001). Regression tolerances did not approach 0 , implying that collinearity was not an issue.

Analysis of effects of optogenetic-assisted silencing of the $V c$ on $P b N$ firing to HEAT and QUI. Four adult male (mean \pm SD body weight, $34.9 \pm$ $5.6 \mathrm{~g}$ ) and 9 adult female (body weight, $27.3 \pm 3.3 \mathrm{~g}$ ) VGAT-ChR2 and littermate $\mathrm{ChR} 2^{-}$mice were used in these studies. Ten $\mathrm{V}^{+} \mathrm{PbN}$ neurons sensitive to HEAT and QUI were acquired from VGAT-ChR2 mice. Six of these neurons yielded response data for both HEAT and QUI on Vc laser and control trials; two cells yielded such data for only QUI, and two for only HEAT. Data for activity to HEAT and QUI on Vc laser and control trials were acquired from $4 \mathrm{~V}^{+} \mathrm{PbN}$ neurons in littermate control mice.

For each stimulus, firing rates in hertz were repeatedly sampled from individual neurons over multiple $\mathrm{Vc}$ laser and control trials to account for normal variance in sensory firing. We aimed to record a block of 10 $\mathrm{Vc}$ laser and 10 control trials during tests involving one stimulus. An interleaved design was used for trial ordering within a block, where following either an initial control or Vc laser trial (varied across cells), alternating pairs of these trials were presented in sequence. Under this design, testing began with either the control or Vc laser condition, and each condition was preceded by itself and the other approximately an equal number of times over the block.

A receiver operating characteristic (ROC) curve (Green and Swets, 1966) quantified the effect of Vc photoinhibition on firing by an individual $\mathrm{PbN}$ neuron to HEAT or QUI. The area under each ROC curve (auROC) estimated the probability that random responses to the stimulus sampled under Vc laser and control conditions could be correctly classified by always assuming that the larger response was control activity. An auROC that approached 1 reflected very good classification, with auROC $=1$ indicating perfect performance. The latter result would arise if stimulus firing was consistently greater on control compared with $\mathrm{Vc}$ laser trials, regardless of trial order. On the other hand, an auROC that approached 0.5 indicated near chance discrimination, with auROC $=0.5$ arising if the control and $\mathrm{Vc}$ laser response distributions completely overlapped. An auROC of $<0.5$ arose when responses on Vc laser trials were frequently larger than control activity.

A permutation method assessed deviation of an observed auROC value from chance performance. Here, we recomputed 1000 auROC values from the response data for the stimulus where before each computation, observed responses were randomly shuffled between Vc laser and control trial labels. This approach resulted in a null distribution of auROC values for the associated stimulus and neuron that reflected random classification performance. An observed auROC that was more extreme than the upper, or lower, 2.5 percentile value of the null distri- 

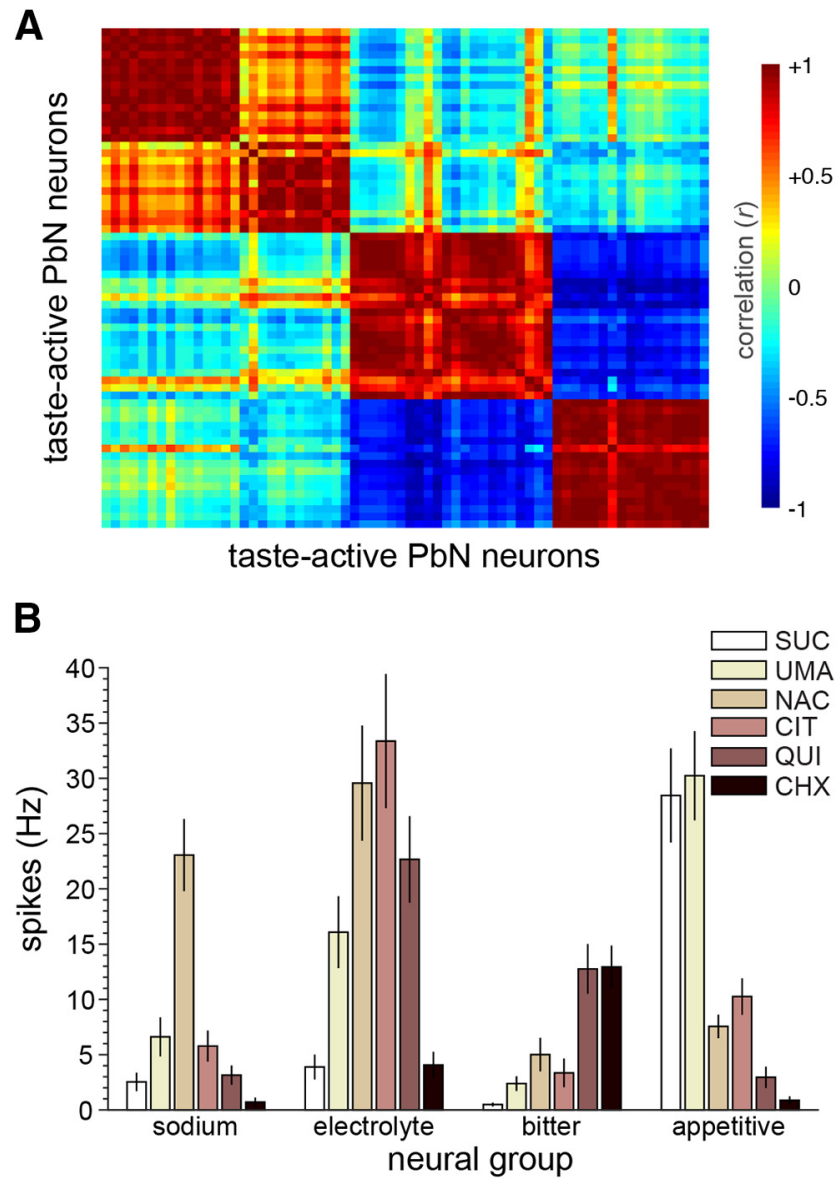

Figure 1. Definition of gustatory neural groups. $A$, Linear correlation matrix for 66 tasteactive $\mathrm{PbN}$ neurons computed from their firing in hertz to six taste stimuli, as in $\boldsymbol{B}$. Cluster analysis identified four major groups of neurons where cells showed marked positive withingroup correlation among their gustatory tuning profiles. The heatmap scale reflects the correlation value. $\boldsymbol{B}$, Mean \pm SEM firing in hertz by sodium $(n=15)$, electrolyte $(n=12)$, bitter $(n=22)$, and appetitive $(n=17)$ group neurons to six taste stimuli (legend), as follows: 500 mm SUC, an umami mixture (UMA), $100 \mathrm{~mm} \mathrm{NAC,} 10 \mathrm{~mm}$ CIT, $10 \mathrm{~mm}$ QUI, and $0.1 \mathrm{~mm}$ CHX. All stimuli were thermally controlled and presented at $28^{\circ} \mathrm{C}$ following oral adaptation to $35^{\circ} \mathrm{C}$.

bution was considered to significantly differ from 0.5 (Veit and Nieder, 2013; Gadziola and Wesson, 2016).

Other analyses, software, and plotting. In some cases, a bootstrap procedure estimated the confidence interval of an estimate, denoted as $\mathrm{CI}^{*}$. In these cases, 1000 bootstrap data resamples were used to calculate the $\mathrm{CI}^{*}$ under the percentile or bias-corrected/accelerated percentile method; no interpretative differences were noted between these methods.

Cells that showed significant firing to CAP were identified by visual inspection of spike trains for a robust, lasting spiking response to CAP; this effect was pronounced for a subpopulation of the recorded $\mathrm{V}^{+} \mathrm{PbN}$ taste cells. Significant firing to other oral stimuli was indexed using a statistical algorithm, as based on the study by Wilson and Lemon (2014).

Tests of equal frequencies across conditions were performed using $\chi^{2}$ goodness-of-fit tests. Evoked spike latencies across neural groups were analyzed using a nonparametric Kruskal-Wallis test to accommodate non-normal data. These statistical procedures, along with ANOVA and multiple regression, were performed using SPSS (version 23.0.0.2, IBM). Reported eta squared values are partial. All other calculations, statistics, and analyses were performed using custom code and built-in functions in MATLAB (release R2018a, MathWorks).

All data plots and graphs were generated using standard routines and custom code in MATLAB. Raw electrophysiological sweeps and thermal traces were exported in bitmap format from Spike2. Illustrations and final figure configurations were produced using Illustrator (version 22.1, Adobe).
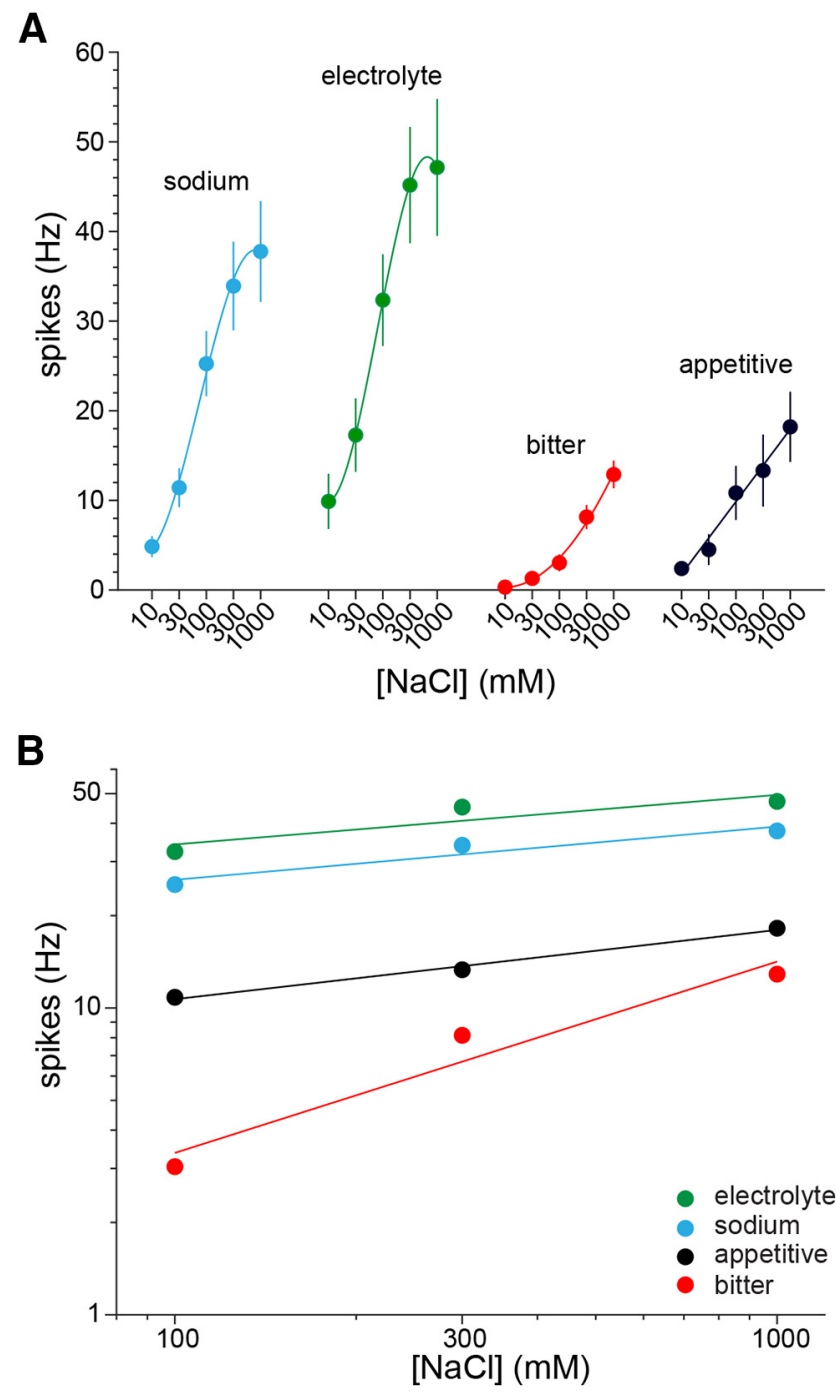

Figure 2. Activity to $\mathrm{NaCl}$ in neural groups. $A$, Mean \pm SEM firing in hertz by sodium $(n=$ 12), electrolyte $(n=7)$, bitter $(n=15)$, and appetitive $(n=11) \mathrm{PbN}$ neurons to the half-log step concentration series of $\mathrm{NaCl}$, shown for each group on a log scale along the abscissa. For each neural group, the plotted line represents the polynomial fit to the mean data that best described the form of the relationship between neural firing and $\mathrm{NaCl}$ concentration, as determined from ANOVA (sodium neurons, cubic fit; electrolyte, cubic; bitter, quadratic; appetitive, linear). $\boldsymbol{B}$, Doubly logarithmic plot of mean firing in hertz by each neural group (legend) to the three highest concentrations of $\mathrm{NaCl}$ from the series. Lines represent least-squares fits of mean values.

Table 1. Numbers of neurons of each type that significantly fired to each concentration of $\mathrm{NaCl}$

\begin{tabular}{llcccrl}
\hline Neural class & $10 \mathrm{~mm}$ & $30 \mathrm{~mm}$ & $100 \mathrm{~mm}$ & $300 \mathrm{~mm}$ & $1000 \mathrm{~mm}$ & $p$ level \\
\hline Sodium & $9(75 \%)$ & $10(83 \%)$ & $12(100 \%)$ & $12(100 \%)$ & $12(100 \%)$ & 0.95 \\
Electrolyte & $5(71 \%)$ & $6(86 \%)$ & $7(100 \%)$ & $7(100 \%)$ & $7(100 \%)$ & 0.97 \\
Bitter & $3(20 \%)$ & $3(20 \%)$ & $8(53 \%)$ & $13(87 \%)$ & $15(100 \%)$ & $0.005^{*}$ \\
Appetitive & $4(36 \%)$ & $6(54 \%)$ & $10(91 \%)$ & $10(91 \%)$ & $11(100 \%)$ & 0.34 \\
\hline
\end{tabular}

For each class, the $p$ level is from a $\chi^{2}$ test $(\mathrm{df}=4)$ of the null hypothesis that equal numbers of cells fired across concentrations. Parenthetical terms denote the percentage of total cells for that type.

*Significant at $\alpha=0.05$.

\section{Results}

Analysis of gustatory response data

Cluster analysis applied to gustatory response profiles for 66 taste-active $\mathrm{PbN}$ neurons revealed four major cellular groups (Fig. 1A). These groups were (1) neurons preferentially activated 

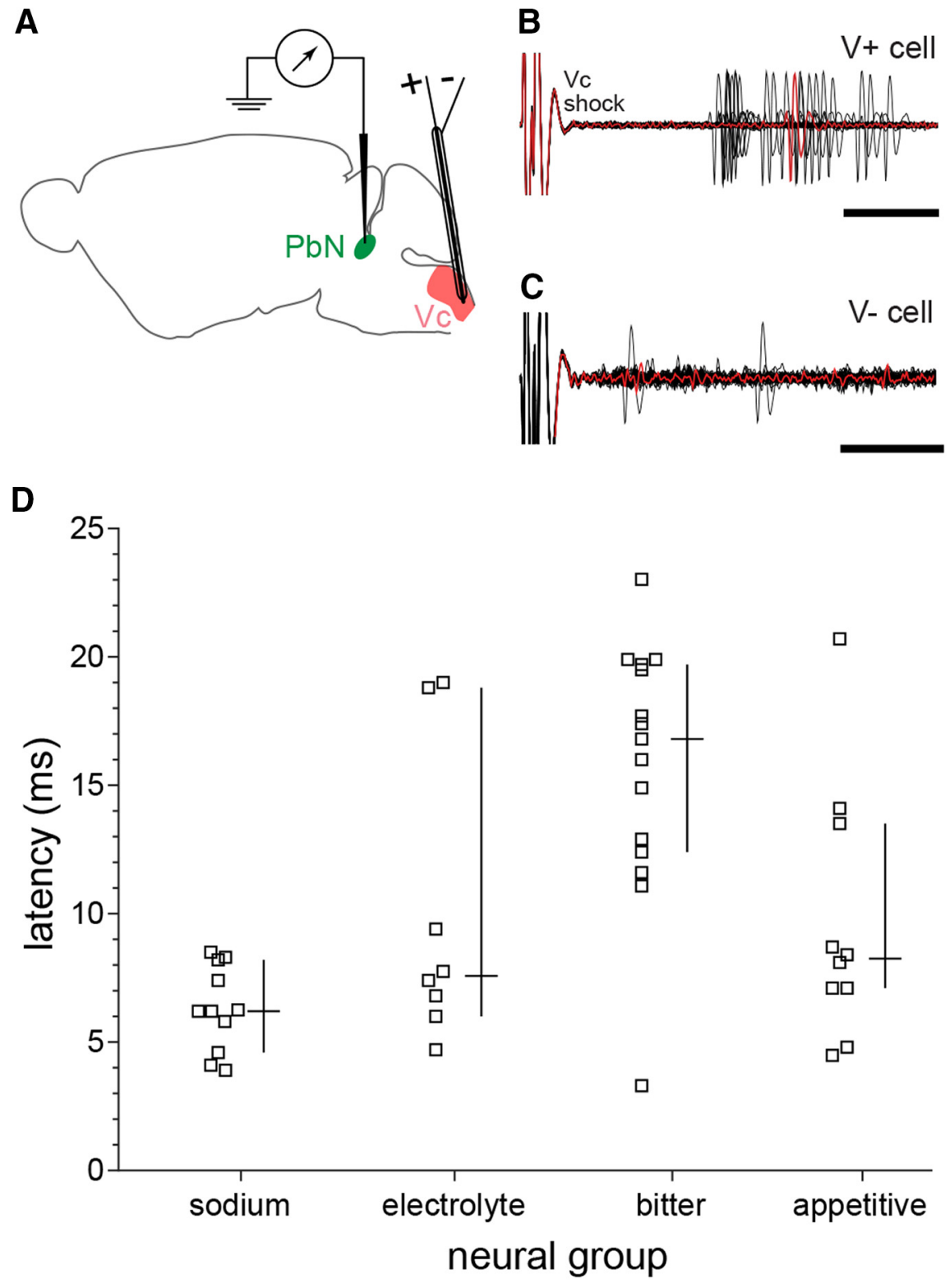

Figure 3. Investigation of electrophysiologic coupling between the $\mathrm{Vc}$ and taste-active $\mathrm{PbN}$ neurons. A, Schematic of experimental setup. Weak electrical pulses were delivered to an oral sensory region of the $V c$ while electrophysiologically monitoring for evoked spikes in PbN gustatory units. $\boldsymbol{B}$, Raw electrophysiological sweeps showing an example PbN gustatory neuron that reliably spiked in response to electrical pulse stimulation of the $\mathrm{Vc}\left(\mathrm{V}^{+}\right.$cell). C, Raw electrophysiological sweeps from an example $\mathrm{PbN}$ gustatory neuron that did not reliably spike to Vc stimulation ( $V^{-}$cell). For $B$ and $C, 40$ sweeps aligned by the electrical stimulus (Vc shock) are superimposed, with an example single sweep shown in red. Scale bars, $5 \mathrm{~ms}$. D, Latencies to fire to Vc stimulation for sodium ( $n=11)$, electrolyte $(n=8)$, bitter $(n=15)$, and appetitive $(n=10) \mathrm{PbN}$ neurons identified as $\mathrm{V}^{+}$. Plot column for each group shows latencies for individual neurons (left, squares), the median latency (right, horizontal line of cross), and the $95 \% \mathrm{Cl}^{*}$ of the median (right, vertical line of cross).

Table 2. Number of $\mathrm{V}^{+}$and $\mathrm{V}^{-}$taste-active $\mathrm{PbN}$ neurons in each gustatory tuning class

\begin{tabular}{llllll}
\hline & Sodium & Electrolyte & Appetitive & Bitter & Total \\
\hline $\mathrm{V}^{+}$ & 11 & 9 & 10 & 16 & 46 \\
$\mathrm{~V}^{-}$ & 4 & 3 & 7 & 6 & 20 \\
\hline
\end{tabular}

by NAC ("sodium” cells), (2) neurons with broad tuning across the electrolyte taste stimuli NAC, CIT, and QUI ("electrolyte" cells), (3) neurons that fired maximally to the preferred taste stimuli SUC and UMA ("appetitive" cells), and (4) neurons that fired strongly to the aversive, in unconditioned form, bitter stim- uli QUI and CHX ("bitter" cells; Fig. 1B). Notwithstanding some differences in stimulus selection, the gustatory profiles that emerged across these neurons were similar to groups in prior neurophysiological data on $\mathrm{PbN}$ taste processing in $\mathrm{B} 6$ mice (Tokita and Boughter, 2016). For the majority of our recorded cells, their location in the $\mathrm{PbN}$ was reconstructed from histological analysis of lesion sites in brain tissue, which is provided at the end of the Results section.

Factorial ANOVA applied to activity to the $\mathrm{NaCl}$ concentration series revealed that $\mathrm{PbN}$ neurons increased their firing to ascending concentrations of $\mathrm{NaCl}$ (main effect of concentration: $F_{(1.3,53.9)}=120.4$, $\left.p=2.4 \times 10^{-17}, \eta^{2}=0.75\right)$ but that the pattern of increase in responding differed across cell groups (group $\times$ concentration interaction: $F_{(3.9,53.9)}=9.6, p=7 \times$ $\left.10^{-6}, \eta^{2}=0.41\right)$. As in Figure $2 A$, both sodium and electrolyte neurons showed the strongest and a steep increase in firing across low (10 and $30 \mathrm{~mm}$ ) to moderate (100 mM) concentrations of $\mathrm{NaCl}$, but approached a plateau in responding to high $\mathrm{NaCl}$ concentrations avoided by mice in behavioral intake tests (300 and $1000 \mathrm{~mm}$; Ninomiya et al., 1989; Eylam and Spector, 2002); this form followed a cubic trend (sodium neurons: $F_{(1,11)}=6.2, p=0.03$, $\eta^{2}=0.36$; electrolyte neurons: $F_{(1,6)}=$ $\left.27.4, p=0.002, \eta^{2}=0.82\right)$. On the other hand, bitter neurons showed comparably flat, near-zero responses to low to moderate (10 to $100 \mathrm{~mm}$ ) concentrations of $\mathrm{NaCl}$, but sharply bowed upward in firing to aversive, high concentrations (300 and $1000 \mathrm{~mm}$ ) following a rapidly accelerating quadratic trend $\left(F_{(1,14)}=28.6, p<0.001\right.$, $\left.\eta^{2}=0.67\right)$. Compared with sodium, electrolyte, and also appetitive cells, which showed a simple linear increase in responding across the entire $\mathrm{NaCl}$ concentration range $\left(F_{(1,10)}=17.9, p=0.002\right.$, $\left.\eta^{2}=0.64\right)$, bitter-class neurons displayed the greatest selectivity for aversive concentrations of $\mathrm{NaCl}$. Similar selectivity for elevated $\mathrm{NaCl}$ was observed in rat $\mathrm{PbN}$ gustatory neurons that fired maximally to bitter stimuli (Geran and Travers, 2009). Furthermore, significantly greater numbers of bitter-class, but not other, neurons activated to high compared with low $\mathrm{NaCl}$ (Table 1). Bitter neurons also showed the largest relative increase in firing across moderate to high $\mathrm{NaCl}$ concentrations. The slope of the log-log concentration-response function for the three highest intensities of $\mathrm{NaCl}$ exceeded 0 for bitter neurons [slope $=0.62(95 \% \mathrm{CI}$ : lower bound $=0.40$; upper bound $=0.84), t_{(13)}=6.1, p=3.9 \times$ $10^{-5}$ ) but was indifferent from 0 for all other cellular types $(p>$ $0.05)$; least-squares fits to mean responses are shown in Figure $2 B$. In summary, high sensitivity to and selectivity for nonpreferred intensities of $\mathrm{NaCl}$ emerged in mouse $\mathrm{PbN}$ bitter- 
class cells. That bitter neurons showed broad responsiveness to unconditionally avoided bitter taste and salt chemicals suggests that bitter cells are involved with aversive coding and agrees with the proposed coactivation of bitter-sensing receptor cells by concentrated salts (Oka et al., 2013).

\section{Stimulation of the $\mathrm{Vc}$ activates $\mathrm{PbN}$ gustatory neurons}

Taste-active $\mathrm{PbN}$ neurons in each group included cells that produced variablelatency spikes in response to weak electrical pulse stimulation of the orosensory $\mathrm{Vc}$ $\left(\mathrm{V}^{+}\right.$neurons; Fig. $\left.3 A, B\right)$ and neurons that did not show reliable evoked activity to orosensory $\mathrm{Vc}$ stimulation $\left(\mathrm{V}^{-}\right.$cells; Fig. $3 A, C)$. Latencies to evoked spikes in $\mathrm{V}^{+} \mathrm{PbN}$ neurons varied with gustatory neuron class (Kruskal-Wallis test, $\mathrm{H}_{3}=$ 16.8, $p=0.001$ ), with $\mathrm{V}^{+}$bitter cells showing the longest median latency (Fig. $3 D$ ) and a latency distribution that significantly differed from that of $\mathrm{V}^{+}$sodium units (Dunn-Bonferroni-adjusted pairwise comparison, $p<0.001)$. This trend may reflect that Vc-parabrachial projection neurons with different morphological or physiological properties transmit to different types of $\mathrm{PbN}$ gustatory cells, or that the number of synapses or pathways that Vc input must cross to reach tasteactive $\mathrm{PbN}$ units varies with cell type. Considering the total numbers (Table 2), the ratio of $\mathrm{V}^{+}$to $\mathrm{V}^{-}$taste-active $\mathrm{PbN}$ neurons (2.3:1) was significantly larger than expected by chance (test of the null ratio of $1: 1, \chi^{2}=10.2$, $\left.\mathrm{df}=1, p=0.001\right)$. Although the sampling of neurons was pseudorandom considering targeted placement of electrodes by coordinates, these data may suggest that areas of the $\mathrm{PbN}$ contain more taste-active neurons receiving contact from the Vc than not.

\section{Sensitivity to nociceptive stimuli in $\mathrm{PbN}$ gustatory neurons}

Forty-eight taste-active $\mathrm{PbN}$ neurons successfully completed testing with all gustatory, thermal, and chemesthetic stimulus trials. From this sample, 33 (69\%) were $\mathrm{V}^{+}$, with a subgroup of $9 \mathrm{~V}^{+} \mathrm{PbN}$ gustatory cells identified to show notably strong, significant firing to the TRPV1 agonist CAP applied to the rostral-ipsilateral tongue. Neuronal responses to CAP were long lasting, continuing after the cessation of stimulus delivery and during oral application of a poststimulus water rinse (Fig. 4). Lingering influence is a hallmark of firing to lingual capsaicin by orosensory chemonociceptive Vc neurons
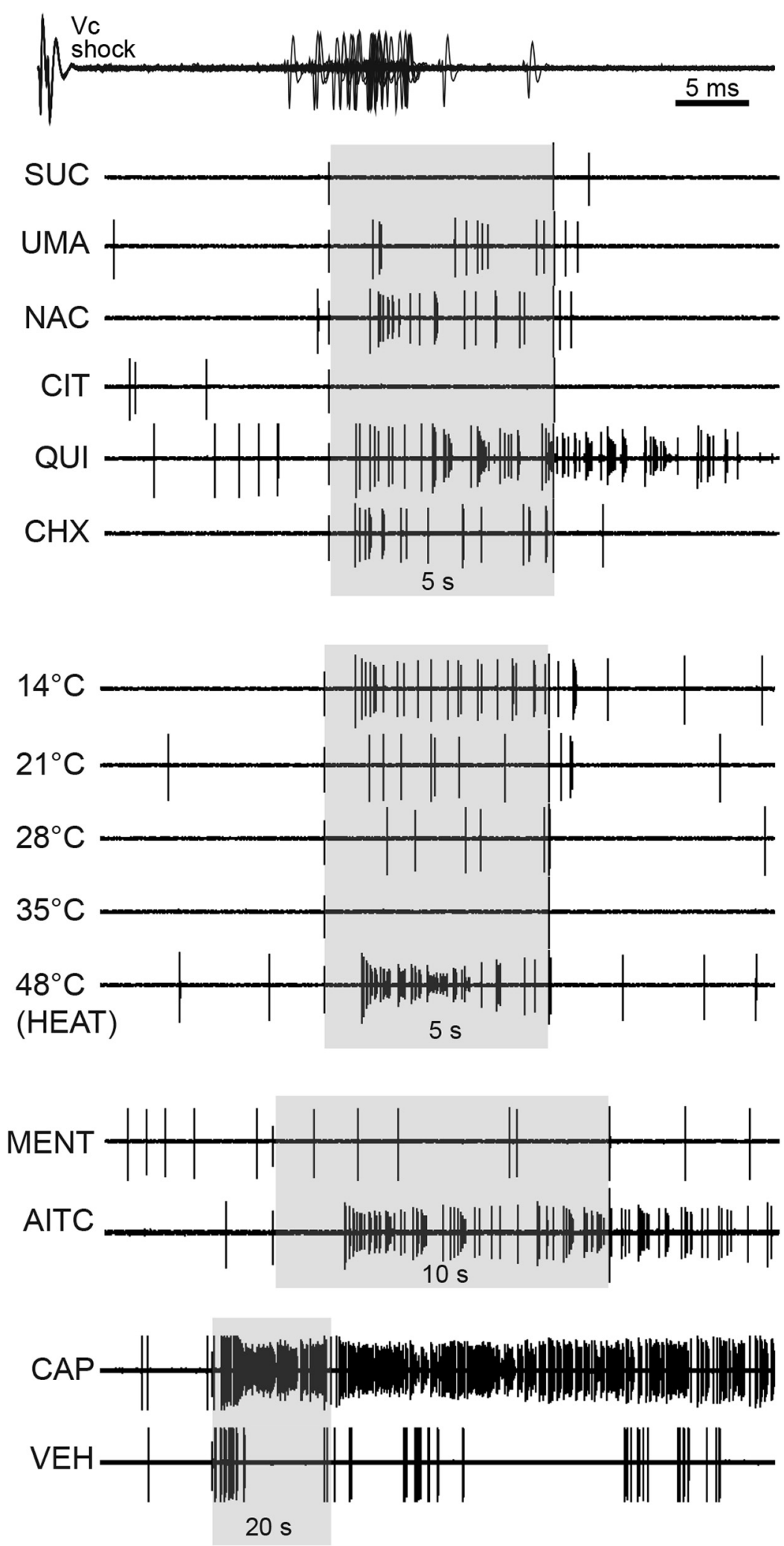

Figure 4. Raw electrophysiological sweeps showing activity by a single PbN neuron to electrical stimulation of the Vc (Vc shock, 40 sweeps superimposed) and oral delivery of taste stimuli (SUC, UMA, NAC, CIT, QUI, and CHX, abbreviated as in Fig. 1), thermaladjusted water $\left[14^{\circ} \mathrm{C}, 21^{\circ} \mathrm{C}, 28^{\circ} \mathrm{C}, 35^{\circ} \mathrm{C}\right.$, and $48^{\circ} \mathrm{C}$ (HEAT), all measured as oral temperature], and chemesthetic stimuli [1.28 mm MENT, 1 mm AITC (mustard oil), 1 mm CAP, and the CAP vehicle (VEH)]. Grayed areas denote the period of oral stimulus application in seconds. 

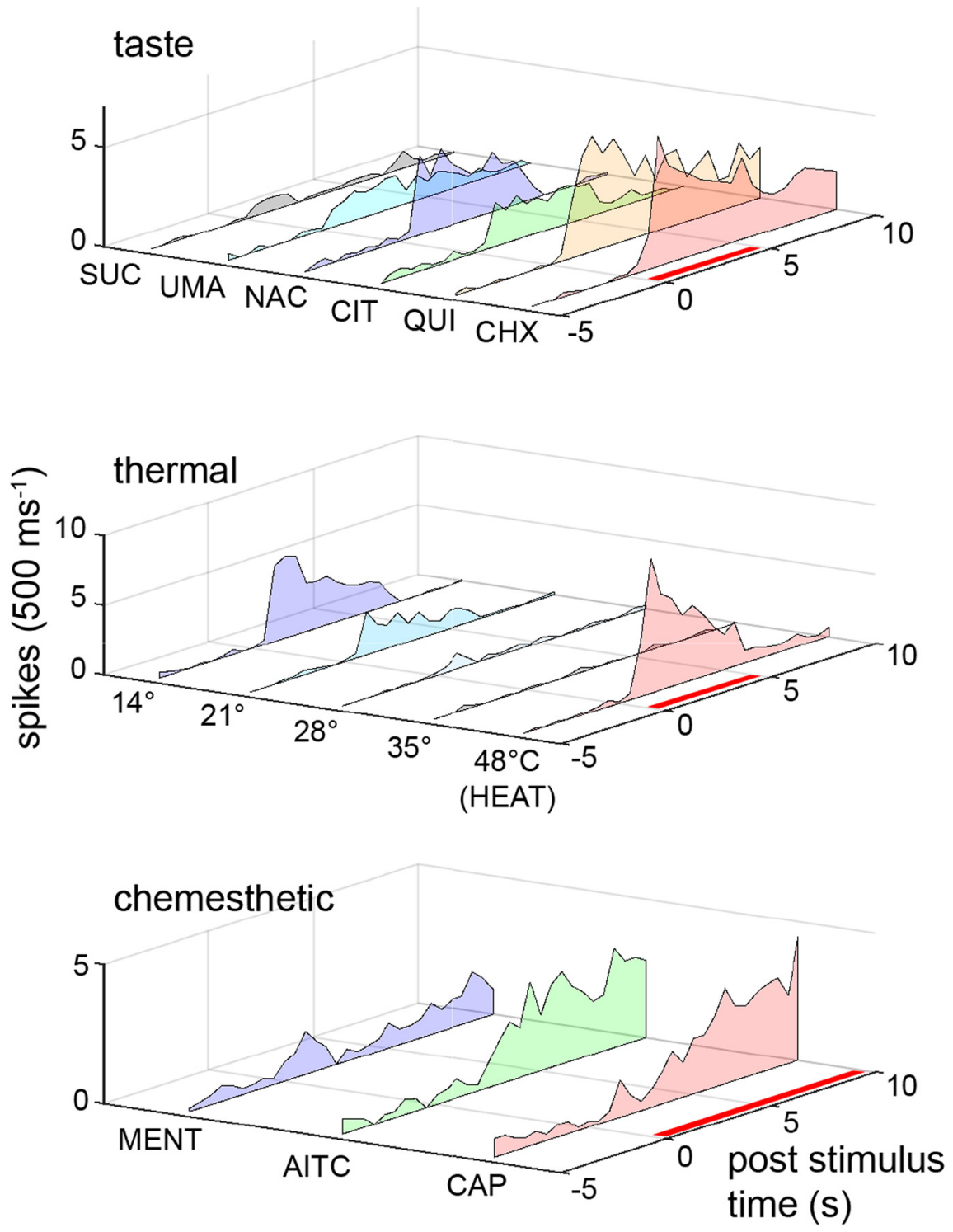

Figure 5. Peristimulus time histograms showing the mean time course of responding (in spikes per $500 \mathrm{~ms}$ ) to taste, thermal, and chemesthetic stimuli (abbreviated as in Figs. 1, 4) across PbN gustatory neurons that significantly fired to oral delivery of capsaicin $(n=9)$. For each plot, the red bar along the time axis denotes stimulus application period.

(Carstens et al., 1998) and would be expected to arise in PbN cells receiving trigeminal-mediated CAP input.

Six of the nine CAP-responsive $\mathrm{PbN}$ gustatory neurons also displayed significant firing to oral delivery of the TRPA1 agonist AITC. This stimulus induced significant firing in only 3 additional CAP-unresponsive units of the sample of 48 defined above. Thus, AITC predominantly excited CAP-responsive taste cells. Cosensitivity to AITC and CAP in individual $\mathrm{PbN}$ neurons follows the frequent coexpression of TRPA1 and TRPV1 by somatosensory and trigeminal fibers (Kobayashi et al., 2005; Bautista et al., 2006) and partial activation of TRPV1 by millimolar concentrations of AITC (Everaerts et al., 2011). Further, AITC and also CAP induced, on average, a unique slow temporal rise in firing in $\mathrm{CAP}$-responsive $\mathrm{PbN}$ gustatory neurons that was not apparent among their responding to thermal or taste stimuli (Fig. 5). This observation agrees with the slow-building responses that lingual mustard oil and capsaicin induce in Vc neurons (Carstens et al., 1998) upstream of the $\mathrm{PbN}$ and supports the notion that responses to CAP and AITC in PbN taste neurons were of trigem- inal origin. CAP-responsive gustatory cells showed only relatively poor or no sensitivity to MENT (Fig. 5), which is a known stimulant of the TRPM8 ion channel expressed by a subset of trigeminal afferents (McKemy et al., 2002).

Finally, all nine CAP-responsive $\mathrm{PbN}$ gustatory neurons significantly fired to HEAT. However, HEAT broadly activated the cellular population, significantly exciting 12 additional CAP-unresponsive neurons in the sample of 48 cells tested with all taste, thermal, and chemesthetic trials. Although noxious heat engages the capsaicin receptor TRPV1 (Caterina et al., 1997), some decorrelation between sensitivity to HEAT and CAP is expected given the evidence for the involvement of nonTRPV1 mechanisms in heat detection. For instance, imaging data from mice on trigeminal ganglion neurons that fire to noxious heat demonstrated that nearly $30 \%$ are insensitive to capsaicin and that pharmacological blockade of TRPV1 reduces firing to high temperatures in only a minority of these cells (Yarmolinsky et al., 2016).

\section{An association between nociceptive and bitter activity in taste-active $\mathrm{PbN}$ neurons}

Visualizing relationships among acrossneuron patterns of response to taste, thermal, and chemesthetic stimuli revealed that $\mathrm{PbN}$ firing to the nociceptive inputs HEAT, AITC, and CAP positively associated with activity to the bitter tastants QUI and CHX (Fig. 6). Unpacking this relationship identified the TRPV1 and TRPA1 agonists CAP and AITC primarily excited bitter-class $\mathrm{PbN}$ neurons-cells with unique high responsiveness to the bitters QUI and CHX (Fig. 1B) and elevated selectivity and sensitivity to aversive concentrations of $\mathrm{NaCl}$ (Fig. 2). Moreover, CAP and AITC induced responses predominantly in bitter taste neurons identified as $\mathrm{V}^{+}$and were poor stimuli for $\mathrm{V}^{-}$cells (Figs. 7, 8), implying that upstream trigeminal coupling in $\mathrm{PbN}$ bitter taste units leads to their cosensitivity to nociceptive stimuli. HEAT was capable of more broadly stimulating $\mathrm{V}^{+}$, and some $\mathrm{V}^{-}, \mathrm{PbN}$ gustatory neurons of variable gustatory tuning, including bitter, electrolyte, and sodium units, albeit HEAT induced notably strong responses in $\mathrm{V}^{+}$bitter taste cells (Figs. 7, 8). Overall, these data implied that for taste-active $\mathrm{PbN}$ neurons, their responsiveness to nociceptive heat and chemesthetic stimuli was strongly tied to their connectivity with ascending trigeminal circuits and sensitivity to bitter tastants.

Whereas $\mathrm{V}^{+}$electrolyte and sodium gustatory neurons frequently showed strong excitatory firing to $21^{\circ} \mathrm{C}$ and $14^{\circ} \mathrm{C}$ (Figs. $7 A, 8 A$ ), these cooling temperatures induced, respectively, only near-zero and marginally higher activity across bitter-class cells (Fig. 8A). In vivo neurophysiological studies in rats and mice have demonstrated that $14^{\circ} \mathrm{C}$ is generally below the threshold (i.e., not 


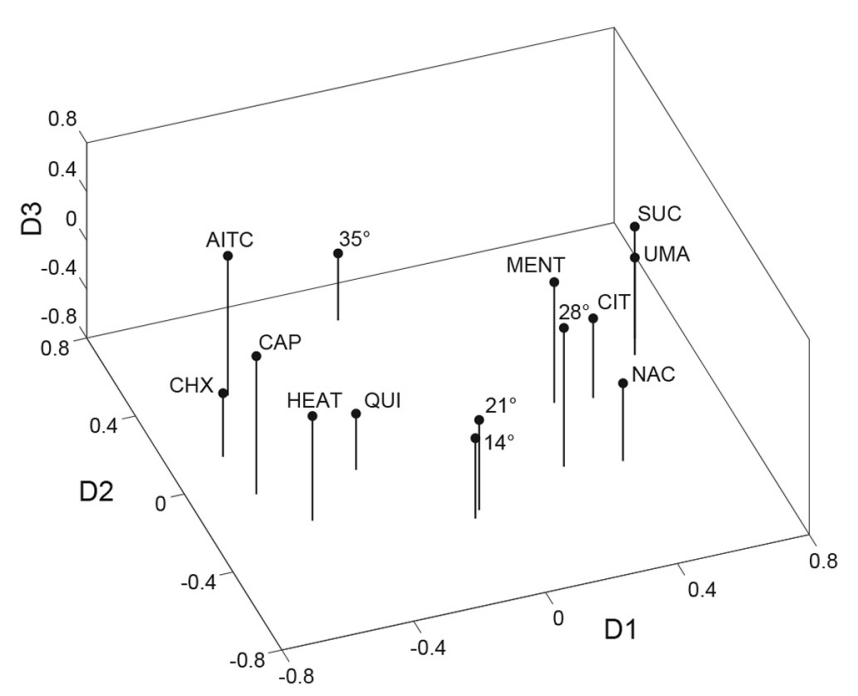

Figure 6. Coordinate space generated by multidimensional scaling analysis showing the organization of responses to taste, thermal, and chemesthetic stimuli across $\mathrm{V}^{+}$and $\mathrm{V}^{-} \mathrm{PbN}$ gustatory neurons $(n=48)$. Stimuli are abbreviated as in Figures 1 and 4 .

cold enough) for cold activation of physiologically defined nociceptive fibers (Simone and Kajander, 1997; Cain et al., 2001). Moreover, the human-reported cold pain threshold can fall below $10^{\circ} \mathrm{C}$ (Morin and Bushnell, 1998). That innocuous cool temperatures were weak stimuli for $\mathrm{PbN}$ bitter neurons involved with aversive taste and heat/chemical nociceptive signaling implies that these cells contribute excitatory firing to an aversive neural code. Along this line, the apparent uptick in responding to $14^{\circ} \mathrm{C}$ in $\mathrm{V}^{+}$bitter cells (Figs. 7,8) opens the possibility that they may strongly fire to noxious cold temperatures more extreme than tested here.

Closer inspection of activity across individual $\mathrm{V}^{+} \mathrm{PbN}$ taste neurons suggested that the correlation between nociceptive and bitter responses was partly bitter stimulus dependent. For instance, although CAP activity was predominantly carried by bitter-class cells firing to QUI and CHX, CHX was a more selective stimulus for this cell type (Fig. 7A). In comparison, QUI effectively stimulated bitter and also electrolyte neurons, with most cells in the latter group showing insensitivity to CAP (Fig. $7 A$ ). Thus, although related to bitter signaling, firing to CAP appears to differentially associate with responding to the bitters QUI and CHX, showing a stronger tie to CHX.

This trend was quantitatively borne out in a multiple regression analysis. Variance in responding to CAP across taste-active $\mathrm{V}^{+} \mathrm{PbN}$ neurons $(n=33)$ was correlated with activity to QUI and CHX (multiple $R=0.64, F_{(2,30)}=10.1, p=4.4 \times 10^{-5}$ ). However, only firing to $\mathrm{CHX}$ showed a significant unique correlation with CAP activity ( $s r$ between firing to CAP and CHX $\left.\left[s r_{\mathrm{CAP} \times \mathrm{CHX}}\right]=+0.48, p=0.002 ; s r_{\mathrm{CAP} \times \mathrm{QUI}}=+0.01, p=0.9\right)$, which follows the unique association between responses to CAP and $\mathrm{CHX}$ visually apparent in plots of $\mathrm{V}^{+}$cellular activity (Fig. $7 A$ ). The same pattern was identified for activity to AITC, where firing to this input by $\mathrm{V}^{+}$cells was associated with activity to both QUI and CHX (multiple $R=0.56, F_{(2,30)}=6.8, p=0.004$ ), with only $\mathrm{CHX}$ contributing significantly to this relationship $\left(s r_{\mathrm{AITC} \times \mathrm{CHX}}=+0.41, p=0.01 ; s r_{\mathrm{AITC} \times \mathrm{QUI}}=+0.06, p=0.7\right.$; Fig. $7 A)$. Thus, sensitivity to the bitter tastant $\mathrm{CHX}$ in $\mathrm{V}^{+} \mathrm{PbN}$ gustatory cells is a notable predictor of their responsiveness to chemesthetic stimuli associated with the activation of the nocisensors TRPV1 and TRPA1. This relationship implies that trigeminal nociceptive inputs to the $\mathrm{PbN}$ at least partly target gustatory neurons with particularly strong and broad responsiveness across bitter tastants, as is associated with neuronal sensitivity to cycloheximide (Geran and Travers, 2006, 2009; Wilson et al., 2012).

Regression analyses also identified that HEAT activity in $\mathrm{V}^{+}$ $\mathrm{PbN}$ taste neurons was associated with activity to $\mathrm{CHX}(R=0.39$, $\left.F_{(1,31)}=5.6, p=0.03\right)$, but not to both CHX and QUI, with the latter condition leading to a nonsignificant multiple $R$ value ( $p=$ 0.074 ). These effects agree with the broader ability of QUI and HEAT to stimulate multiple cellular types in addition to bitterclass neurons (Figs. 7A, 8A).

Multiple regression analyses were not performed for $\mathrm{V}^{-}$tasteactive $\mathrm{PbN}$ neurons due to low sample size and the observation that somatosensory nociceptive firing was markedly blunted in $\mathrm{V}^{-}$compared with $\mathrm{V}^{+}$taste-active cells (Figs. 7, 8). Altogether, the above data suggest that there is a predictive relationship between activation to nociceptive inputs and bitter tastants in gustatory-active $\mathrm{PbN}$ cells that is tied to their receipt of input from upstream trigeminal nuclei.

\section{Trigeminal input contributes to nociceptive activity in $\mathrm{PbN}$ bitter taste neurons}

To delineate whether Vc input was involved with sensitivity to nociceptive stimuli in trigeminal-coupled gustatory cells, responses to HEAT were recorded from $\mathrm{V}^{+} \mathrm{PbN}$ bitter taste neurons during optogenetic-assisted photoinhibition of the orosensory Vc. This was accomplished using VGAT-ChR2 mice, which allowed optogenetic control of ChR2 in Vc inhibitory neurons and, thus, afforded laser-induced rapid and reversible suppression of oral sensory firing in the $\mathrm{Vc}$ (Fig. 9A) during $\mathrm{PbN}$ recordings. On average, $\mathrm{PbN}$ gustatory cells tested in optogenetic studies demonstrated bitter-class tuning profiles (Fig. 10A). Overall, 146 responses to brief applications of HEAT were acquired from eight $\mathrm{PbN}$ cells in VGAT-ChR2 mice under laser-on (Vc laser) and laser-off (control) conditions. Raw data from the application of this procedure to one of these neurons are shown in Figure 9B, where spike firing to HEAT was visibly suppressed over $10 \mathrm{Vc}$ laser trials compared with 10 control trials. For this unit, responses in hertz to HEAT were always lower on $\mathrm{Vc}$ laser trials, resulting in an auROC of 1 .

ROC permutation tests applied to seven individual units revealed that five showed significantly reduced firing to HEAT over $10 \mathrm{Vc}$ laser trials compared with 10 control trials $(p<0.05$; Fig. $11 A)$. Permutation statistics could not be computed for the one remaining neuron due to acquisition of only three trials per laser-on and control conditions. However, HEAT activity by this cell was always lower on Vc laser trials (auROC $=1$ ). Thus, in VGAT-ChR2 mice, Vc photoinhibition suppressed firing to HEAT in six of eight $(75 \%) \mathrm{V}^{+}$taste-active $\mathrm{PbN}$ cells tested. Moreover, several of these neurons showed reduced median firing to HEAT on Vc laser trials compared with control, with nonoverlapping 95\% $\mathrm{CI}^{\star}$ s between conditions (Fig. 11B) implying that such reductions were significant. While activity to HEAT did show reduction, it was not completely suppressed (i.e., to zero spikes) by Vc photoinhibition in most cases, potentially reflecting network complexity, as discussed below.

To evaluate the stimulus specificity of the optogenetic effect, responses to QUI were recorded during Vc laser and control trials from six of the above $\mathrm{PbN}$ neurons and also two additional $\mathrm{V}^{+}$ PbN bitter taste units ( $n=8$ total) in VGAT-ChR2 mice. Six cells completed 10 pairs of these trials; two cells completed 4 and 7 trial pairs, respectively, making 142 QUI trials in total that were available for analysis. In contrast to its reduced firing to HEAT during 
A

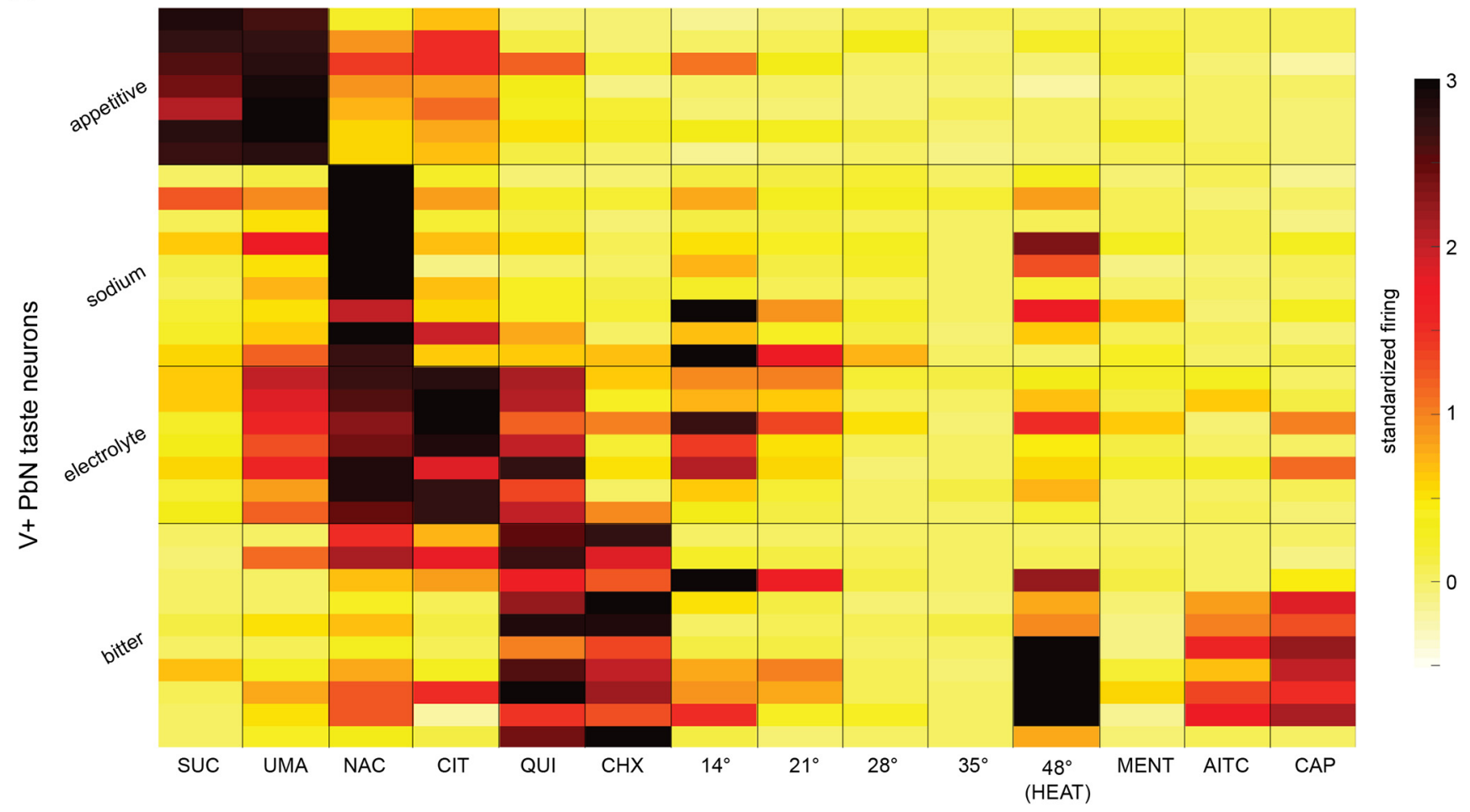

B

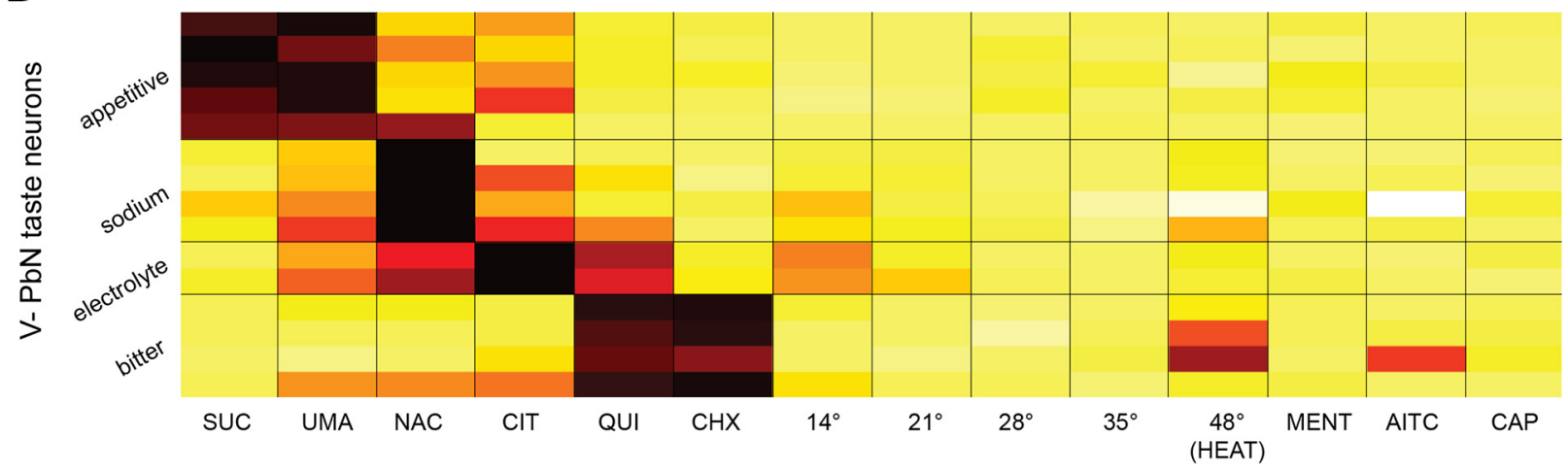

Figure 7. $\quad \boldsymbol{A}, \boldsymbol{B}$, Heatmaps showing standardized firing to taste, thermal, and chemesthetic stimuli (abbreviated as in Figs. 1, 4) for individual appetitive, sodium, electrolyte, and bitter PbN neurons (each row gives response data for an individual cell) that showed evidence of electrophysiological coupling with the $\mathrm{Vc}\left(\boldsymbol{A}, \mathrm{V}^{+} \mathrm{PbN}\right.$ taste neurons) or did not show such coupling ( $\boldsymbol{B}, \mathrm{V}^{-} \mathrm{PbN}$ taste neurons). The heat scale in $\boldsymbol{A}$ applies to both panels. Note that firing to capsaicin is corrected for activity to the capsaicin vehicle.

Vc photoinhibition, the example $\mathrm{PbN}$ neuron in Figure $9 \mathrm{~B}$ gave visibly similar responses to QUI over $10 \mathrm{Vc}$ laser and 10 control trials, with ROC permutation statistics revealing no significant difference in its firing to QUI between conditions (auROC = $0.62, p>0.05)$. Overall, ROC permutation tests identified that firing to QUI did not differ between Vc laser and control trials for six of eight neurons (75\%) recorded from VGAT-ChR2 mice $(p>0.05$; Fig. 11A). Effects in the two remaining cells appeared minor given their low firing rates to QUI on several control trials (Fig. 11C, VGAT-ChR2 neurons 1 and 2). Moreover, all VGATChR2 neurons showed 95\% $\mathrm{CI}^{\star}$ values for median firing to QUI that overlapped between $\mathrm{Vc}$ laser and control conditions (Fig. $11 C)$, which differed from the nonoverlap of these intervals observed for VGAT-ChR2 cellular activity to HEAT (Fig. 11B).

As a procedural control, we evaluated whether the shortened stimulus-response period used in optogenetic studies influenced the measurement of activity to HEAT or QUI relative to the longer-duration responses to these stimuli acquired during the initial block of thermal or taste trials. For each stimulus, neural firing rates, in $\mathrm{Hz}$, calculated from the initial trial block (5 s period) and the first no laser (control) trial of the Vc photoinhibition/control test sequence ( $2 \mathrm{~s}$ period) were compared using a paired $t$ test; for both stimuli, the Jarque-Bera statistic indicated that differences in neural firing between conditions were normally distributed. The number of spikes evoked per second did not differ between the 5 and 2 s stimulus-response windows for $\operatorname{HEAT}\left(t_{(7)}=-2.2, p=0.07\right)$ and QUI $\left(t_{(7)}=1.6, p=0.1\right.$; Fig. $10 B)$. Thus, the shortened period provided a reasonable window to index neural activity to HEAT and QUI over repeated trials.

Finally, to control for nonspecific laser effects on brain tissue, responses to HEAT and QUI were recorded from bitter-class $\mathrm{V}^{+}$ $\mathrm{PbN}$ taste neurons $(n=4)$ in littermate $\mathrm{ChR} 2^{-}$mice during Vc laser and control trials. All PbN neurons sampled from ChR2 mice completed 10 pairs of these trials for QUI (80 QUI trials total); for HEAT, three PbN neurons completed $10 \mathrm{Vc}$ laser on/ off trial pairs, whereas one cell completed 7 pairs (74 HEAT trials 
overall). ROC permutation tests applied to individual neurons revealed no differences in firing to HEAT or QUI between laser-on and control conditions in ChR2 ${ }^{-}$animals ( $p>0.05$; Fig. $11 A$ ). Moreover, all cells acquired from these mice showed $95 \% \mathrm{CI}^{\star}$ values for median activity to HEAT and QUI that overlapped between $\mathrm{Vc}$ laser and control trials (Fig. $11 B, C$ ), unlike VGAT-ChR2 cellular responses to HEAT (Fig. 11B). These results attributed the light-induced suppression of $\mathrm{PbN}$ sensory firing observed in VGAT-ChR2 mice to optogenetic activation of Vc inhibitory circuits.

Altogether, the above data show temporary suppression of neural activity in an orosensory region of the Vc differentially impacted $\mathrm{PbN}$ unit responses to nociceptive and bitter taste stimulation. Specifically, photoinhibition of Vc circuits caused a reliable and predominant reduction in firing to HEAT compared with QUI in a subset of Vc-coupled PbN bitter taste neurons. This finding implies that trigeminal pathways contribute to nociceptive activity in taste-active $\mathrm{PbN}$ cells.

\section{Nociceptive and aversive taste signals converge in the lateral $\mathrm{PbN}$}

Analysis of histological data revealed a role for spatial location within the $\mathrm{PbN}$ in bitter-nociceptive overlap. Considering taste-active $\mathrm{PbN}$ neurons tested for electrophysiologic coupling with the Vc, reconstruction of recording sites for 40 of these units implied that the numbers of $\mathrm{V}^{+}(n=15)$ and $\mathrm{V}^{-}(n=12)$ cells acquired from the dorsal lateral, central lateral, and medial $\mathrm{PbN}$ did not reliably differ $\left(\chi^{2}=0.33\right.$, df $=1, p=0.56$; Fig. $12 A)$. Cells of all gustatory types were found in these regions. Yet, of 12 neurons reconstructed in the external lateral $\mathrm{PbN}$, all were $\mathrm{V}^{+}$, with $8(67 \%)$ of these cells identified as bitter-class neurons firing strongly to the bitters QUI and CHX. As expected given that the majority were bitter cells, external lateral $\mathrm{V}^{+} \mathrm{PbN}$ neurons showed significantly longer latencies to fire to $\mathrm{Vc}$ stimulation than nonexternal lateral $\mathrm{V}^{+} \mathrm{PbN}$ units (Mann-Whitney $U=$ $142, p=0.01$; Fig. 3). The frequency of bitter neurons encountered in the external lateral $\mathrm{PbN}$ implies that strongly bitter responsive gustatory projections partly target this parabrachial region. Moreover, significant activity to CAP, a hallmark of TRPV1 activation, emerged only in external lateral $\mathrm{PbN}$ neurons, suggesting that ascending trigeminal nociceptive inputs also target this brain area. Putting these trends together, all external lateral bitter-class neurons that were tested with CAP (six of eight cells) significantly fired to CAP; the two bitter neurons untested with CAP did fire to HEAT. Thus, lateral parabrachial circuits contain neurons sensitive to avoided taste and oral nociceptive inputs.

The relationship between the external lateral $\mathrm{PbN}$ and bitterclass cells was not perfectly inclusive, as 33\% of neurons identi-
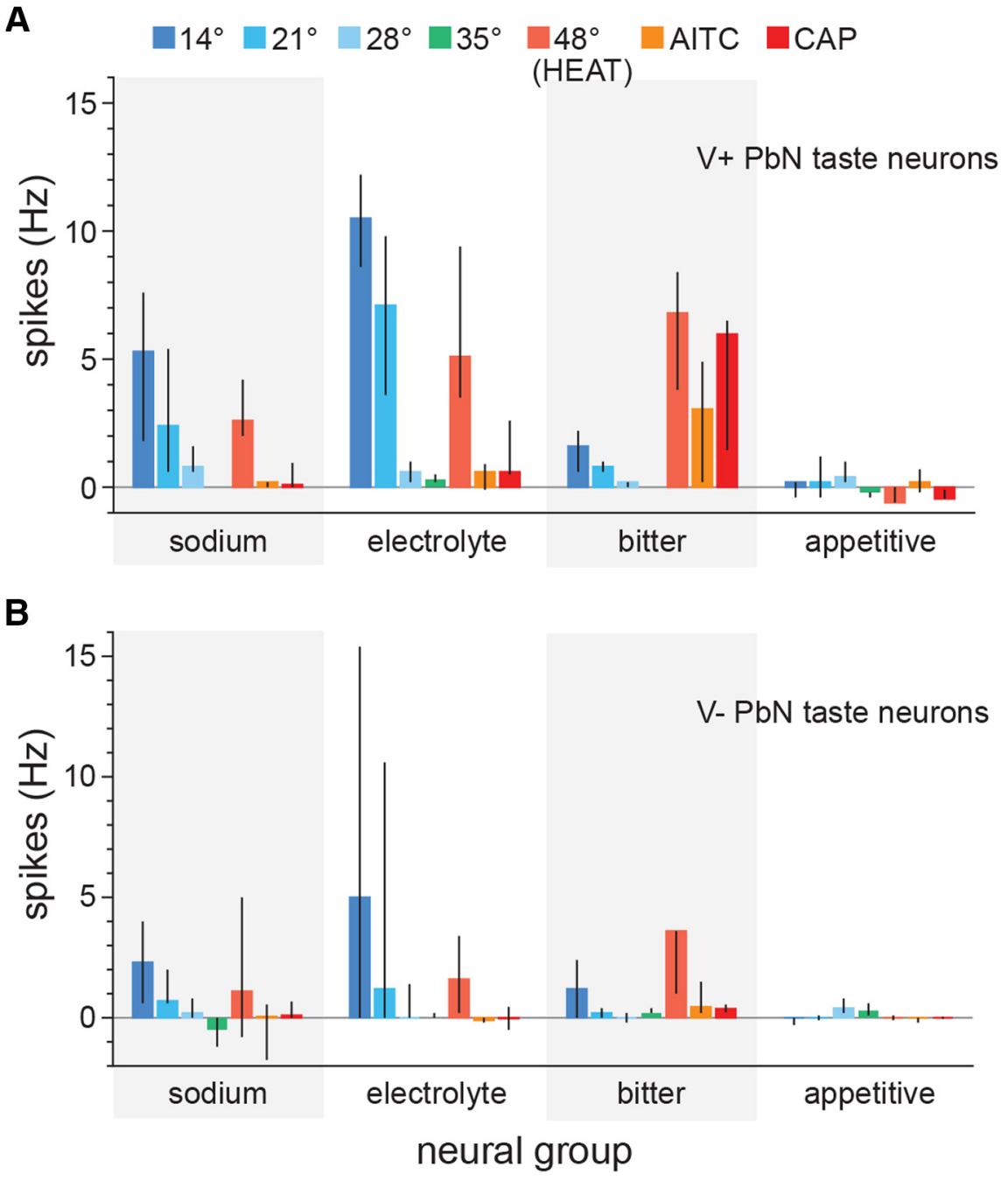

Figure 8. Responses to somatosensory stimuli in sodium, electrolyte, bitter, and appetitive $\mathrm{PbN}$ gustatory neurons. $\boldsymbol{A}, \mathrm{Me}-$ dian $\pm 68 \% \mathrm{Cl}{ }^{*}$ firing in hertz to thermal $\left[14^{\circ} \mathrm{C}, 21^{\circ} \mathrm{C}, 28^{\circ} \mathrm{C}, 35^{\circ} \mathrm{C}\right.$, and $\left.48^{\circ} \mathrm{C}(\mathrm{HEAT})\right]$ and chemesthetic $[1$ mu AITC (mustard oil) and

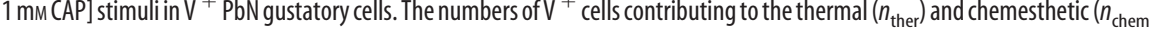
$n_{\text {ther }}=15$ and $n_{\text {chem }}=10$; appetitive, both $n_{\text {ther }}$ and $n_{\text {chem }}=7 . \boldsymbol{B}$, Same as $\boldsymbol{A}$ except for $V^{-}$PbN gustatory neurons. The numbers of cells contributing to the thermal and chemesthetic response data for each group follow: sodium neurons, both $n_{\text {ther }}$ and $n_{\text {chem }}=4$; electrolyte, $n_{\text {ther }}=3$ and $n_{\text {chem }}=2 ;$ bitter, $n_{\text {ther }}=5$ and $n_{\text {chem }}=4$; appetitive, $n_{\text {ther }}=6$ and $n_{\text {chem }}=5$. For both panels, cellular activity to capsaicin is corrected for activity to the capsaicin vehicle. The left/right order of the stimuli in the legend (A) gives their order in the bar plot for each group.

fied in this subnucleus were electrolyte responsive (Fig. 12A); with one exception, these cells fired to nociceptive stimuli such as HEAT. Nevertheless, these cells were a minority. Moreover, histological reconstruction of recording sites for $\mathrm{V}^{+} \mathrm{PbN}$ bitter taste neurons tested in optogenetic studies, which included cells showing Vc-dependent activity to noxious heat, implied that these neurons were all located in the external lateral $\mathrm{PbN}$ (Fig. 12B), providing further evidence that lateral parabrachial circuits support overlap of bitter taste and somatosensory nociceptive activity.

\section{Discussion}

Electrical stimulation of the orosensory Vc excited multiple types of parabrachial gustatory neurons. We show here that a subpopulation of these cells responsive to the bitter taste stimuli quinine and cycloheximide, and with elevated sensitivity to high (aversive) salt, cofired to oral delivery of agonists of the nocisensors TRPV1 and TRPA1 on somatosensory fibers, including capsai- 
A Vc neuron
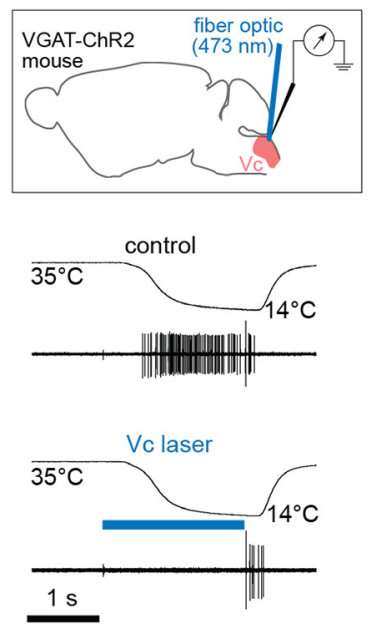

\section{B $\mathrm{PbN}$ neuron}

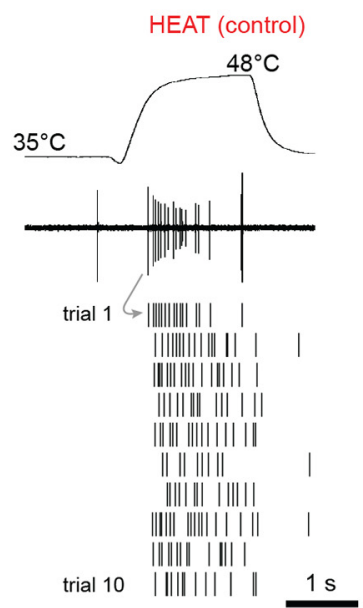

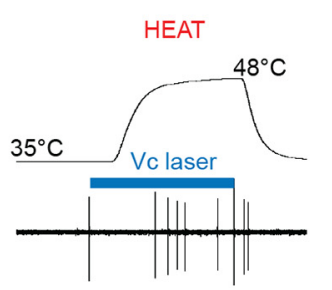

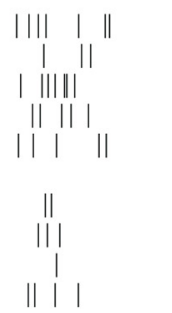

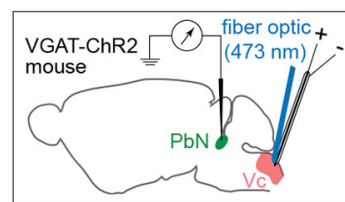

QUI (control)

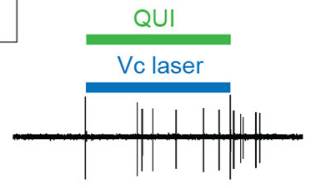

|| || || |||||

||| | ||| || ||

| |||||||| $\mid$

||||| ||| |

|||| || | | || |

||||||| || ||

| | || | ||

| ||| | | ||

\|\||||| $\mid$
|| | | | | || ||

|| | | || || ||

| || || | | || || || ||

| ||| || | ||||

| | ||| ||| |

|| | | ||

|l||| |

|l | |

|| || || |l||| |

Figure 9. Example effects of optogenetic-assisted suppression of oral sensory neural activity in VGAT-ChR2 mice. A, Raw electrophysiological sweeps showing firing by a Vcneuron in a VGAT-ChR2 mouse to an oral cooling ramp (shown, measured as oral temperature) presented by itself (control trial) and in unison with blue laser light delivery to the Vc (Vc laser trial), which engaged local inhibitory neurons. Spiking by this cell to cooling was notably strong under the control condition but was suppressed on the Vc laser trial; note spiking recovered immediately following the removal of light (bottom trace). Inset shows experiment schematic, where the recording electrode and fiber optic for laser delivery both targeted the same area of the Vc. Note that $V c$ unit recording was not part of the present analyses but is shown here to illustrate the optogenetic-assisted inhibitory effect. B, Activity by a $V^{+}$PbN bitter taste neuron in a VGAT-ChR2 mouse during oral presentations of noxious heat $\left(48^{\circ} \mathrm{C}, \mathrm{HEAT}\right.$ ) over 10 control and $10 \mathrm{Vc}$ laser trials (two leftmost columns), and $10 \mathrm{~mm}$ QUI over 10 control and $10 \mathrm{Vc}$ laser trials (two rightmost columns). The raw electrophysiological sweep for the first trial of each stimulus/condition is shown to illustrate the conversion of neurophysiological data to raster spikes; thermal traces on HEAT trials reflect oral temperature. For this PbN neuron, firing to HEAT was markedly and repeatedly suppressed on Vc laser compared with control trials, whereas QUI activity did not differ between conditions; see Results for details. Inset shows experiment schematic, where the recording electrode was positioned in the $\mathrm{PbN}$, whereas the fiber optic for light delivery and the electrical stimulation electrode both targeted the same oral sensory-verified region of the $\mathrm{Vc}$.
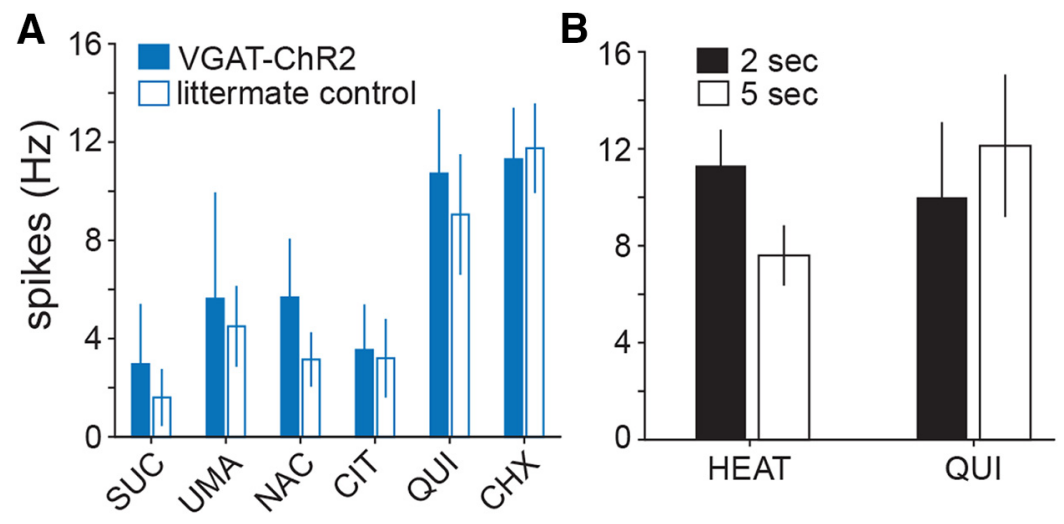

Figure 10. Gustatory response characteristics of neurons tested in optogenetic studies. $A$, Mean \pm SEM firing in hertz to taste stimuli by $\mathrm{V}^{+} \mathrm{PbN}$ neurons acquired from VGAT-ChR2 (10 cells) and littermate control (4 cells) mice. Stimuli are $500 \mathrm{~mm}$ SUC, an umami mixture (UMA), $100 \mathrm{~mm} \mathrm{NAC,} 10 \mathrm{~mm}$ CIT, $10 \mathrm{~mm}$ QUI, and $0.1 \mathrm{~mm}$ CHX. On average, these neurons showed bitter-class gustatory response profiles, firing strongly to QUI and CHX. $B$, Mean \pm SEM firing in hertz by $\mathrm{V}^{+} \mathrm{PbN}$ neurons in VGAT-ChR2 mice to oral delivery of noxious heat at $48^{\circ} \mathrm{C}(\mathrm{HEAT}, n=8)$ and QUI $(n=8)$ calculated from the longer stimulus period of the initial trial $(5 \mathrm{~s})$ and the shortened period of the first no-laser (control) trial of the $\mathrm{V}$ c photoinhibition/control test sequence $(2 \mathrm{~s})$. No difference in the number of spikes that emerged per second was noted between the 5 and 2 s response windows. For this analysis and plot, the means for 5 and 2 s responses to HEAT were composed of data from eight neurons that successfully completed the Vc photoinhibition/control test sequence; means for 5 and 2 s responses to QUI included data from six of these cells and two additional neurons.

cin, mustard oil, and noxious heat. Firing to cycloheximide, which marks strongly bitter responsive gustatory units (Geran and Travers, 2006, 2009; Wilson et al., 2012), was an important identifier of $\mathrm{PbN}$ neurons dually sensitive to bitter and nociceptive input, given broader activation of bitter and other cells by quinine. Further, acute photoinhibition of Vc circuits reversibly suppressed nociceptive heat activity in a subset of bitter-active $\mathrm{PbN}$ cells. Altogether, these data imply that trigeminal pathways contribute to oral nociceptive firing in $\mathrm{PbN}$ taste neurons strongly activated by aversive bitter stimuli. Such neurons could serve roles in protective coding beyond only taste.

Although our results imply that trigeminal sensory signals reach parabrachial gustatory units, it is important to consider potential alternative mechanisms. Earlier data from rats suggest that millimolar (i.e., taste-like) concentrations of quinine can stimulate trigeminal lingual nerve fibers in vivo (Pittman and Contreras, 1998) and raise intracellular calcium $\left(\left[\mathrm{Ca}^{2+}\right]_{\mathrm{i}}\right)$ in cultured capsaicinsensitive trigeminal ganglion neurons at room temperature (Liu and Simon, 1998). Such results would imply that presynaptic trigeminal neurons mediate nociceptive and bitter overlap in the $\mathrm{PbN}$. Yet, a different picture emerges from functional data on the $\mathrm{Vc}$, which was presently linked to nociceptive firing in $\mathrm{PbN}$ bitter taste cells. Mouse oral somatosensory Vc neurons were found to be unresponsive to temperature-controlled taste stimuli, including millimolar quinine, that activated gustatory cells in the NTS (Lemon et al., 2016). Further, Simons et al. (2003b) asked whether the lingual presence of an elevated concentration of quinine could excite rat oral sensory Vc neurons, including chemonociceptive capsaicin-sensitive units, but found no response. Thus, Vc neurons are insensitive to quinine, implying Vccoupled $\mathrm{PbN}$ bitter neurons receive quinine signals from the gustatory NTS, with somatosensory input contributing to their firing to nociceptive stimuli such as tongue-applied capsaicin. The con- 


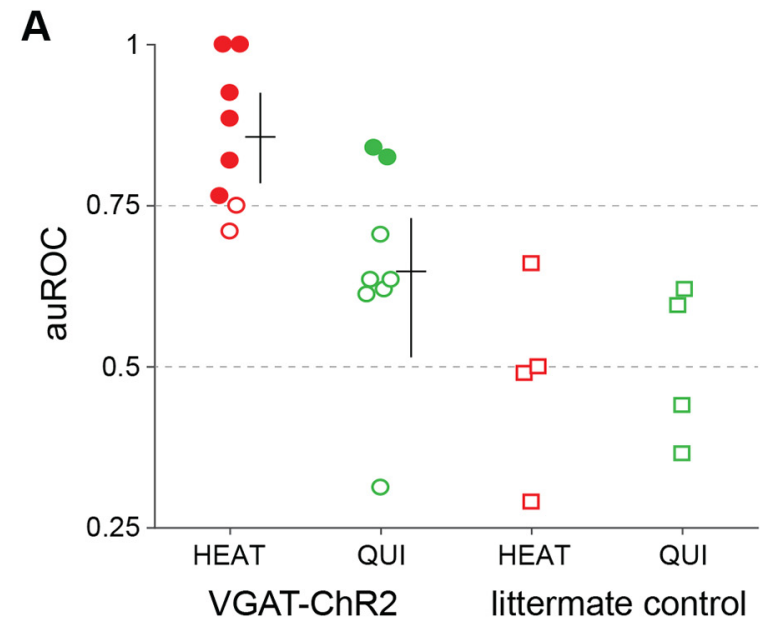

B

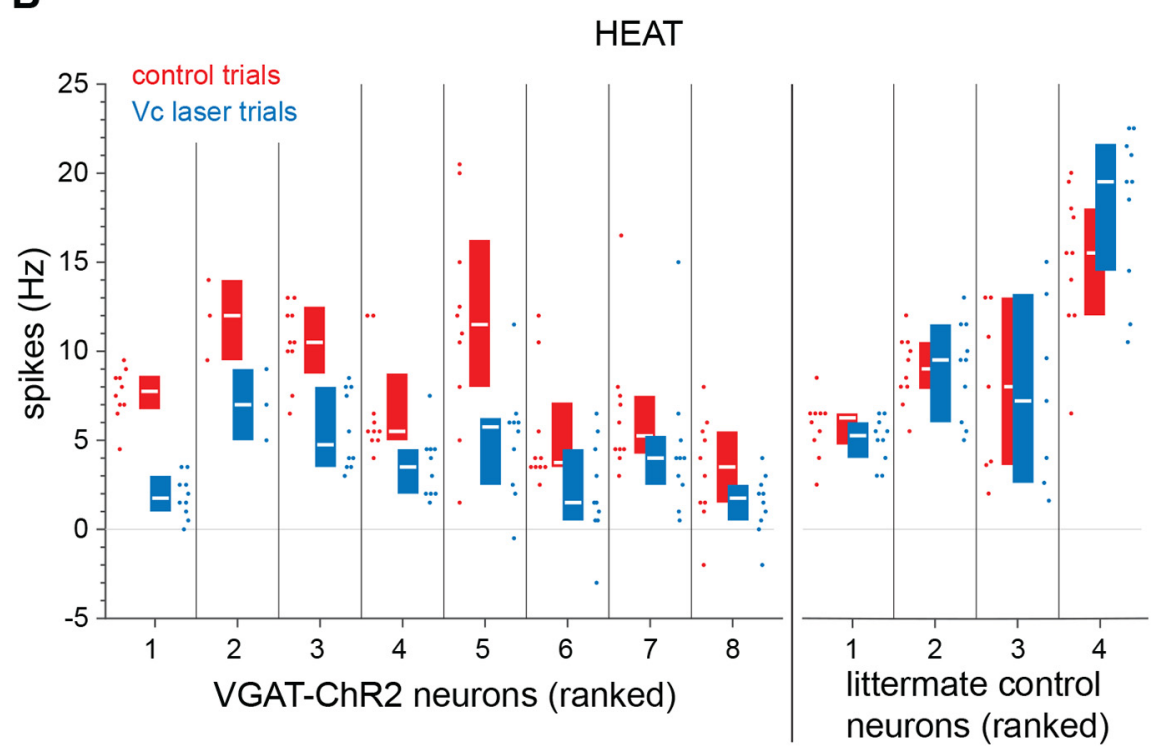

C

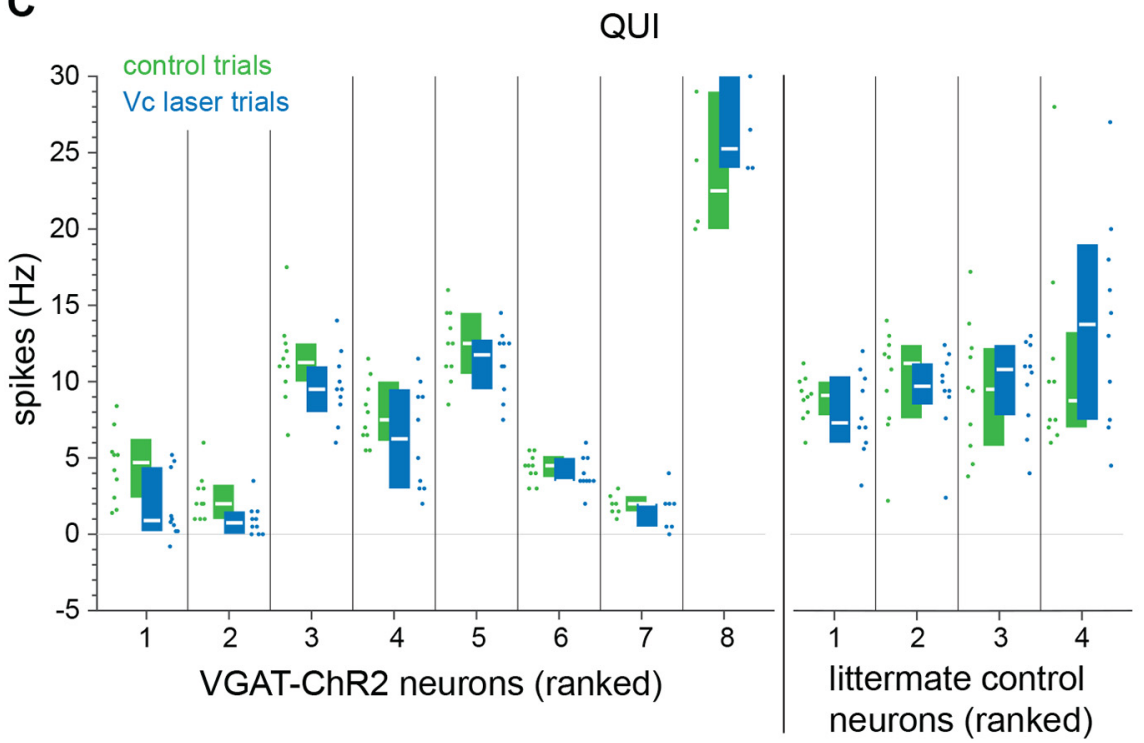

Figure 11. Analyses of firing to noxious heat $\left(48^{\circ} \mathrm{C}\right.$, HEAT) and $10 \mathrm{~mm}$ QUI for multiple Vc-coupled PbN bitter neurons during optogenetic-assisted inhibition targeted to the $\mathrm{Vc}$. $A$, Plotted are auROC values for individual PbN neurons from VGAT-ChR2 mice (circles) and ChR2 ${ }^{-}$littermate control mice (squares) computed from their firing to HEAT (red) or QUI (green) on Vc laser and control trials. Filled markers represent auROC values that equal 1 or significantly differ from chance; open markers indicate auROC values that do not differ from chance. For neurons acquired from VGAT-ChR2 mice, the median auROC value (horizontal line of verse that capsaicin could excite peripheral gustatory afferents is not strongly supported (Dahl et al., 1997; Simons et al., 2003a; Boucher et al., 2014).

An additional mechanism for bitternociceptive overlap is apparent in the afferent system of the solitary chemosensory cells (SCCs) of the airways. SCCs express some known bitter taste receptors and contact peptidergic fibers of nasal trigeminal and vagal nerves (Finger et al., 2003; Tizzano et al., 2011). While potentially leading to bitter activity in somatosensory neurons, the involvement of this system with the present results is unclear. Airway stimulation was beyond the scope of our study, albeit taste solutions delivered whole-mouth may have reached SCC-containing pharyngeal fields innervated by the superior laryngeal (SL) nerve (Tizzano et al., 2011). Nevertheless, SL fibers in mice respond to water and do not increase firing to quinine (Ohkuri et al., 2012). Cycloheximide was reported to raise $\left[\mathrm{Ca}^{2+}\right]_{\mathrm{i}}$ in rodent vomeronasal SCCs (Ogura et al., 2010) and excite nasal trigeminal fibers (Finger et al., 2003), but at concentrations 25 and 100 times greater, respectively, than the presently used 0.1 mM. In mice, $0.1 \mathrm{~mm}$ cycloheximide causes aversion in taste-salient behavioral assays (Boughter et al., 2005) and excites NTS gustatory neurons (Wilson et al., 2012). Other data show that nasal SCCs do not express a taste receptor for cycloheximide (Finger et al., 2003) and do not increase $\left[\mathrm{Ca}^{2+}\right]_{\mathrm{i}}$ in response to up to 20 mM cycloheximide, which caused decreased $\left[\mathrm{Ca}^{2+}\right]_{\mathrm{i}}$ or cell death (Gulbransen et al., 2008).

Presently, optogenetic-assisted activation of inhibitory processes intrinsic to the Vc suppressed firing to noxious heat in $\mathrm{V}^{+} \mathrm{PbN}$ bitter cells, implicating $\mathrm{Vc}$ projections for nociceptive sensitivity by these neurons. Yet, such suppression was imperfect and variable across units. This

cross) and $95 \% \mathrm{Cl}^{*}$ of the median (vertical line of cross) is shown to the right of their auROC scores for HEAT and QUI. $B$, Each numbered column shows for an individual $\mathrm{PbN}$ neuron all responses in hertz to HEAT (points) and the $95 \% \mathrm{Cl}^{*}$ of the median HEAT response (vertical bar spans the interval, with the median marked by a white horizontal line) on control (red) and Vc laser (blue) trials. Neurons from VGAT-ChR2 and ChR2 ${ }^{-}$littermate control mice are ranked along the abscissa in descending order of their respective auROC values for HEAT, shown in $A$. C, Numbered columns show for individual neurons all responses in hertz to QUI (points) and the $95 \% \mathrm{Cl}^{*}$ of the median QUI response (as in $\boldsymbol{B}$ ) on control (green) and Vc laser (blue) trials. Neurons are ranked as in $\boldsymbol{B}$ based on auROC values for QUI. 

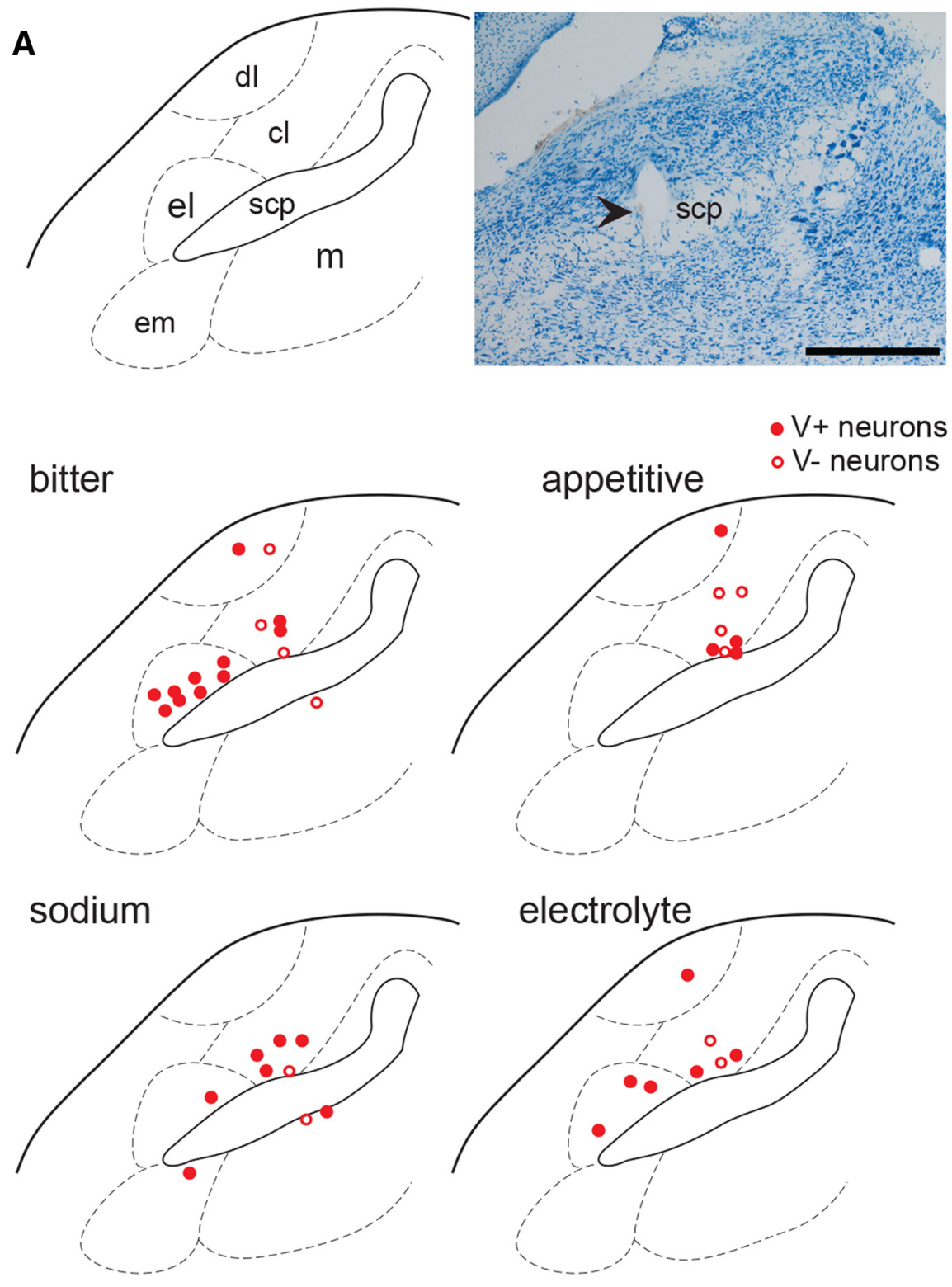

B

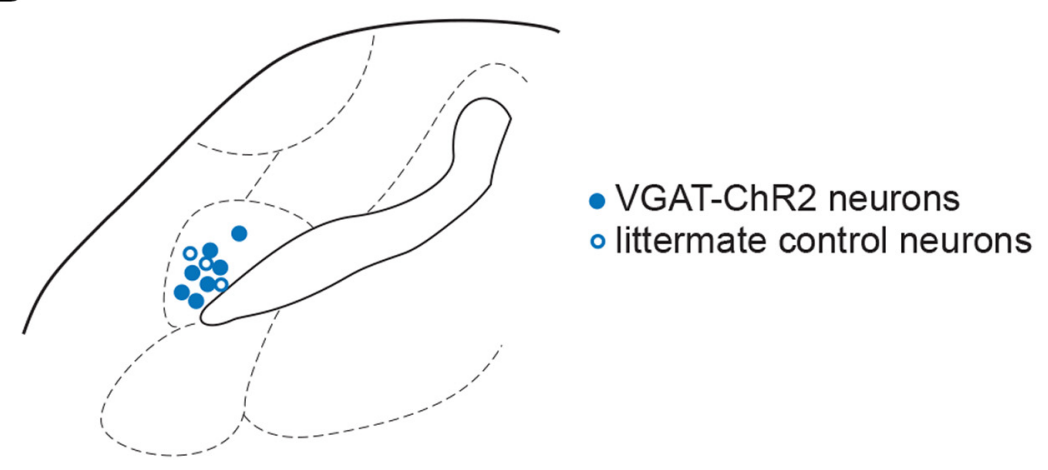

Figure 12. Histological analysis of recording sites. $A$, Reconstruction of recording electrode locations (circles) for bitter ( $n=$ $15)$, appetitive $(n=8)$, sodium $(n=9)$, and electrolyte $(n=8) \mathrm{PbN}$ neurons tested for electrophysiologic coupling with the $\mathrm{Vc}$ The legend denotes whether recorded cells were identified as $\mathrm{V}^{+}$or $\mathrm{V}^{-}$. Photograph depicts an electrolytic lesion (arrowhead) made in the lateral PbN where a bitter-class neuron was acquired. Scale bar, $500 \mu \mathrm{m}$. $\boldsymbol{B}$, Reconstruction of recording electrode locations for $\mathrm{V}^{+} \mathrm{PbN}$ neurons acquired from VGAT-ChR2 $(n=7)$ and littermate control $(n=3)$ mice used in optogenetic studies. For $\boldsymbol{A}$ and $\boldsymbol{B}$, plotted circles mark estimated placement of electrode tip; the electrolytic lesions induced in brain tissue were typically larger. Reconstructed lesion sites are plotted on only one coronal plane of the PbN for simplicity; actual lesion sites were observed may reflect an ability of heat to partly engage pathways untargeted by our optogenetic manipulation. Relatedly, trigeminal fibers associated with nociception are evidenced to ascend to the lateral $\mathrm{PbN}$ (Cavanaugh et al., 2011; Rodriguez et al., 2017), where nociceptive and bitter cellular activity overlapped. As an additional consideration, sudden perturbation of $\mathrm{Vc}$ input may disrupt processing of off-target projections arriving in the $\mathrm{PbN}$ (Otchy et al., 2015) including gustatory afferents, which may account for the minor reductions in quinine activity noted during Vc inhibition. Nevertheless, that inhibition focused to the Vc predominantly suppressed firing to noxious heat compared with quinine implies that separate pathways are involved with transmitting these signals to common $\mathrm{PbN}$ neurons.

Electrical excitation of the Vc stimulated taste-active neurons in multiple parabrachial areas, albeit $\mathrm{V}^{+}$bitternociceptive cells populated the external region of the lateral $\mathrm{PbN}$. The lateral $\mathrm{PbN}$ is established to receive anatomical projections from Vc cells (Cechetto et al., 1985; Bernard et al., 1989). Efferent projections of external and lateral $\mathrm{PbN}$ areas include the central nucleus of the amygdala, with parabrachioamygdaloid neurons firing to noxious thermal and mechanical stimulation of trigeminalsupplied orofacial receptive fields (Bernard and Besson, 1990). The external and lateral $\mathrm{PbN}$ subnuclei also receive input from NTS neurons, including caudally located cholecystokinin and dopamine $\beta$-hydroxylase cells associated with feeding (Roman et al., 2016) and neurons mediating signals for aversive taste. In rats, external medial and external lateral $\mathrm{PbN}$ neurons show c-Fos expression following intraoral infusion of quinine (Yamamoto et al., 1994) and comprise gustatory neuron types that fire to bitters, including quinine and cycloheximide, and possess anterior and posterior oral receptive fields innervated by the facial and glossopharyngeal nerves, which supply taste input to NTS neurons presynaptic to the $\mathrm{PbN}$ (Halsell and Travers, 1997; Geran and Travers, 2009). Altogether, these data point to the $\mathrm{PbN}$ as a brain site where aversive taste and nociceptive processing would overlap.

$\leftarrow$

$\sim 60 \mu \mathrm{m}$ around this rostrocaudal location. dl, Dorsal latera nucleus; cl, central lateral nucleus; el, external lateral PbN; em, external medial $\mathrm{PbN} ; \mathrm{m}$, medial parabrachial area; scp, superior cerebellar peduncle. 
The present nociceptive-active bitter taste neurons in the lateral $\mathrm{PbN}$ appear to convey an aversive or protective signal serving multiple systems as opposed to only taste. Involvement of lateral $\mathrm{PbN}$ cells with protective processing is also supported by data showing that this brain region links nociceptive and avoidance circuits from different areas of the body to limbic structures. In rats, noxious heat and pinch applied to the spinal nerve-supplied hindpaws and tail activates lateral $\mathrm{PbN}$ parabrachioamygdaloid neurons cosensitive to nociceptive stimulation of orofacial trigeminal fields (Bernard and Besson, 1990). Furthermore, lateral $\mathrm{PbN}$ neurons that express calcitonin gene-related peptide (CGRP), which are involved with the parabrachioamygdaloid circuit (Schwaber et al., 1988), can respond to malaise, itch, extended food consumption, and unconditioned and conditioned aversive stimuli (Campos et al., 2018). Recent articles have discussed lateral PbN CGRP cells as encoding a general "stop" signal to ward off harm and posit that this cellular population would also fire to aversive taste (Campos et al., 2018; Palmiter, 2018). Although the present work did not index the genetic signature of nociceptive-active bitter cells, their presence in the external lateral $\mathrm{PbN}$ and upstream coupling with the $\mathrm{Vc}$ suggest that they may be part of the lateral $\mathrm{PbN}$ cellular population that transmits aversive signals to the amygdala.

Bitter taste activity in external lateral $\mathrm{PbN}$ cells may stem from projections from NTS regions that receive lingual-tonsillar glossopharyngeal nerve fibers. These fibers innervate caudal tongue gustatory receptors and terminate at levels of the NTS projecting to the external lateral PbN (Hamilton and Norgren, 1984; Bernard et al., 1989; Herbert et al., 1990). Notably, glossopharyngeal fibers show robust firing to the lingual presence of cycloheximide (Danilova and Hellekant, 2003), identified here as a partial predictor of nociceptive-active, bitter-class $\mathrm{PbN}$ neurons. That glossopharyngeal nerve input may drive bitter activity in these units further supports their involvement in protective coding, as severing the glossopharyngeal nerve impairs rejective, but not discriminative, rat oral behavioral responses to bitter stimuli (St. John and Spector, 1998; Geran and Travers, 2011).

Several questions remain concerning taste-somatosensory integration in the $\mathrm{PbN}$. Vc pulse stimulation excited $\mathrm{V}^{+}$tasteactive $\mathrm{PbN}$ neurons sensitive to oral cooling. Yet, the cooling agent and TRPM8 agonist menthol only poorly stimulated Vccoupled $\mathrm{PbN}$ cooling units. Whether cooling signals in these cells are contributed by the subpopulation of menthol-insensitive, cooling-responsive trigeminal sensory neurons (Bautista et al., 2007) awaits direct investigation. Notably, some PbN neurons, particularly appetitive-class cells, did not fire to somatosensory stimuli but generated spikes to Vc pulse stimulation. Speculatively, the function of such coupling may come on-line under conditions presently untested.

In closing, here we found that neural messages associated with bitterness and oral pain are partly relayed to $\mathrm{PbN}$ neurons dually linked to gustatory and trigeminal processing. Our results agree with the postulate that $\mathrm{PbN}$ circuits mediate multisystem convergence associated with protection and homeostasis and implicate classically identified "gustatory" neurons in this process.

Recordings from alert rodents suggest $\mathrm{PbN}$ neural signaling concerning homeostasis is partly dynamic. For example, intraduodenal infusion of lipid can rapidly reduce $\mathrm{PbN}$ gustatory firing to caloric tastants, potentially to balance neural sensitivity with nutritional status (Hajnal et al., 1999). Moreover, the temporal dynamics of parabrachial gustatory responses can convey information about stimulus palatability (Baez-Santiago et al., 2016). These and our results highlight that understanding the circuit properties and broader sensory repertoire of gustatoryactive brain cells is needed to delineate their roles in taste processing and beyond.

\section{References}

Abe J, Hosokawa H, Okazawa M, Kandachi M, Sawada Y, Yamanaka K, Matsumura K, Kobayashi S (2005) TRPM8 protein localization in trigeminal ganglion and taste papillae. Brain Res Mol Brain Res 136:91-98. CrossRef Medline

Baez-Santiago MA, Reid EE, Moran A, Maier JX, Marrero-Garcia Y, Katz DB (2016) Dynamic taste responses of parabrachial pontine neurons in awake rats. J Neurophysiol 115:1314-1323. CrossRef Medline

Bautista DM, Jordt SE, Nikai T, Tsuruda PR, Read AJ, Poblete J, Yamoah EN, Basbaum AI, Julius D (2006) TRPA1 mediates the inflammatory actions of environmental irritants and proalgesic agents. Cell 124:1269-1282. CrossRef Medline

Bautista DM, Siemens J, Glazer JM, Tsuruda PR, Basbaum AI, Stucky CL, Jordt SE, Julius D (2007) The menthol receptor TRPM8 is the principal detector of environmental cold. Nature 448:204-208. CrossRef Medline

Bernard JF, Besson JM (1990) The spino(trigemino)pontoamygdaloid pathway: electrophysiological evidence for an involvement in pain processes. J Neurophysiol 63:473-490. CrossRef Medline

Bernard JF, Peschanski M, Besson JM (1989) A possible spino (trigemino)ponto-amygdaloid pathway for pain. Neurosci Lett 100:83-88. CrossRef Medline

Boucher Y, Simons CT, Faurion A, Azérad J, Carstens E (2003) Trigeminal modulation of gustatory neurons in the nucleus of the solitary tract. Brain Res 973:265-274. CrossRef Medline

Boucher Y, Simons CT, Carstens MI, Carstens E (2014) Effects of gustatory nerve transection and/or ovariectomy on oral capsaicin avoidance in rats. Pain 155:814-820. CrossRef Medline

Boughter JD Jr, Raghow S, Nelson TM, Munger SD (2005) Inbred mouse strains C57BL/6J and DBA/2J vary in sensitivity to a subset of bitter stimuli. BMC Genet 6:36. CrossRef Medline

Braud A, Vandenbeuch A, Zerari-Mailly F, Boucher Y (2012) Dental afferents project onto gustatory neurons in the nucleus of the solitary tract. J Dent Res 91:215-220. CrossRef Medline

Cain DM, Khasabov SG, Simone DA (2001) Response properties of mechanoreceptors and nociceptors in mouse glabrous skin: an in vivo study. J Neurophysiol 85:1561-1574. CrossRef Medline

Campos CA, Bowen AJ, Roman CW, Palmiter RD (2018) Encoding of danger by parabrachial CGRP neurons. Nature 555:617-622. CrossRef Medline

Carstens E, Kuenzler N, Handwerker HO (1998) Activation of neurons in rat trigeminal subnucleus caudalis by different irritant chemicals applied to oral or ocular mucosa. J Neurophysiol 80:465-492. CrossRef Medline

Caterina MJ, Schumacher MA, Tominaga M, Rosen TA, Levine JD, Julius D (1997) The capsaicin receptor: a heat-activated ion channel in the pain pathway. Nature 389:816-824. CrossRef Medline

Caterina MJ, Leffler A, Malmberg AB, Martin WJ, Trafton J, Petersen-Zeitz KR, Koltzenburg M, Basbaum AI, Julius D (2000) Impaired nociception and pain sensation in mice lacking the capsaicin receptor. Science 288 : 306-313. CrossRef Medline

Cavanaugh DJ, Chesler AT, Bráz JM, Shah NM, Julius D, Basbaum AI (2011) Restriction of transient receptor potential vanilloid-1 to the peptidergic subset of primary afferent neurons follows its developmental downregulation in nonpeptidergic neurons. J Neurosci 31:10119-10127. CrossRef Medline

Cechetto DF, Standaert DG, Saper CB (1985) Spinal and trigeminal dorsal horn projections to the parabrachial nucleus in the rat. J Comp Neurol 240:153-160. CrossRef Medline

Chang FC, Scott TR (1984) Conditioned taste aversions modify neural responses in the rat nucleus tractus solitarius. J Neurosci 4:1850-1862. CrossRef Medline

Chase SM, Young ED (2007) First-spike latency information in single neurons increases when referenced to population onset. Proc Natl Acad Sci U S A 104:5175-5180. CrossRef Medline

Dahl M, Erickson RP, Simon SA (1997) Neural responses to bitter compounds in rats. Brain Res 756:22-34. CrossRef Medline

Danilova V, Hellekant G (2003) Comparison of the responses of the chorda tympani and glossopharyngeal nerves to taste stimuli in C57BL/6J mice. BMC Neurosci 4:5. CrossRef Medline 
Dhaka A, Earley TJ, Watson J, Patapoutian A (2008) Visualizing cold spots: TRPM8-expressing sensory neurons and their projections. J Neurosci 28:566-575. CrossRef Medline

Ellingson JM, Silbaugh BC, Brasser SM (2009) Reduced oral ethanol avoidance in mice lacking transient receptor potential channel vanilloid receptor 1. Behav Genet 39:62-72. CrossRef Medline

Everaerts W, Gees M, Alpizar YA, Farre R, Leten C, Apetrei A, Dewachter I, van Leuven F, Vennekens R, De Ridder D, Nilius B, Voets T, Talavera K (2011) The capsaicin receptor TRPV1 is a crucial mediator of the noxious effects of mustard oil. Curr Biol 21:316-321. CrossRef Medline

Eylam S, Spector AC (2002) The effect of amiloride on operantly conditioned performance in an $\mathrm{NaCl}$ taste detection task and $\mathrm{NaCl}$ preference in C57BL/6J mice. Behav Neurosci 116:149-159. CrossRef Medline

Felizardo R, Boucher Y, Braud A, Carstens E, Dauvergne C, Zerari-Mailly F (2009) Trigeminal projections on gustatory neurons of the nucleus of the solitary tract: a double-label strategy using electrical stimulation of the chorda tympani and tracer injection in the lingual nerve. Brain Res 1288: 60-68. CrossRef Medline

Finger TE, Böttger B, Hansen A, Anderson KT, Alimohammadi H, Silver WL (2003) Solitary chemoreceptor cells in the nasal cavity serve as sentinels of respiration. Proc Natl Acad Sci U S A 100:8981-8986. CrossRef Medline

Franklin K, Paxinos G (2008) The mouse brain in stereotaxic coordinates, Ed 3. San Diego: Academic.

Gadziola MA, Wesson DW (2016) The neural representation of goaldirected actions and outcomes in the ventral striatum's olfactory tubercle. J Neurosci 36:548-560. CrossRef Medline

Gauriau C, Bernard JF (2002) Pain pathways and parabrachial circuits in the rat. Exp Physiol 87:251-258. CrossRef Medline

Geran LC, Travers SP (2006) Single neurons in the nucleus of the solitary tract respond selectively to bitter taste stimuli. J Neurophysiol 96:25132527. CrossRef Medline

Geran LC, Travers SP (2009) Bitter-responsive gustatory neurons in the rat parabrachial nucleus. J Neurophysiol 101:1598-1612. CrossRef Medline

Geran LC, Travers SP (2011) Glossopharyngeal nerve transection impairs unconditioned avoidance of diverse bitter stimuli in rats. Behav Neurosci 125:519-528. CrossRef Medline

Ginestal E, Matute C (1993) Gamma-aminobutyric acid-immunoreactive neurons in the rat trigeminal nuclei. Histochemistry 99:49-55. CrossRef Medline

Green DM, Swets JA (1966) Signal detection theory and psychophysics. New York: Wiley.

Grossman SE, Fontanini A, Wieskopf JS, Katz DB (2008) Learning-related plasticity of temporal coding in simultaneously recorded amygdalacortical ensembles. J Neurosci 28:2864-2873. CrossRef Medline

Gulbransen BD, Clapp TR, Finger TE, Kinnamon SC (2008) Nasal solitary chemoreceptor cell responses to bitter and trigeminal stimulants in vitro. J Neurophysiol 99:2929-2937. CrossRef Medline

Guo ZV, Li N, Huber D, Ophir E, Gutnisky D, Ting JT, Feng G, Svoboda K (2014) Flow of cortical activity underlying a tactile decision in mice. Neuron 81:179-194. CrossRef Medline

Hajnal A, Takenouchi K, Norgren R (1999) Effect of intraduodenal lipid on parabrachial gustatory coding in awake rats. J Neurosci 19:7182-7190. CrossRef Medline

Halsell CB, Travers SP (1997) Anterior and posterior oral cavity responsive neurons are differentially distributed among parabrachial subnuclei in rat. J Neurophysiol 78:920-938. CrossRef Medline

Hamilton RB, Norgren R (1984) Central projections of gustatory nerves in the rat. J Comp Neurol 222:560-577. CrossRef Medline

Haring JH, Henderson TA, Jacquin MF (1990) Principalis- or parabrachialprojecting spinal trigeminal neurons do not stain for GABA or GAD. Somatosens Mot Res 7:391-397. CrossRef Medline

Herbert H, Moga MM, Saper CB (1990) Connections of the parabrachial nucleus with the nucleus of the solitary tract and the medullary reticular formation in the rat. J Comp Neurol 293:540-580. CrossRef Medline

Jordt SE, Bautista DM, Chuang HH, McKemy DD, Zygmunt PM, Högestätt ED, Meng ID, Julius D (2004) Mustard oils and cannabinoids excite sensory nerve fibres through the TRP channel ANKTM1. Nature 427: 260-265. CrossRef Medline

Kobayashi K, Fukuoka T, Obata K, Yamanaka H, Dai Y, Tokunaga A, Noguchi K (2005) Distinct expression of TRPM8, TRPA1, and TRPV1 mRNAs in rat primary afferent neurons with adelta/c-fibers and colocal- ization with trk receptors. J Comp Neurol 493:596-606. CrossRef Medline

Lemon CH, Kang Y, Li J (2016) Separate functions for responses to oral temperature in thermo-gustatory and trigeminal neurons. Chem Senses 41:457-471. CrossRef Medline

Li J, Lemon CH (2015a) Influence of stimulus and oral adaptation temperature on gustatory responses in central taste-sensitive neurons. J Neurophysiol 113:2700-2712. CrossRef Medline

Li J, Lemon CH (2015b) Trigeminal convergence onto oral sensory neurons in the mouse nucleus of the solitary tract associates with gustatory and thermal tuning. Chem Senses 40:575.

Liu L, Simon SA (1998) Responses of cultured rat trigeminal ganglion neurons to bitter tastants. Chem Senses 23:125-130. CrossRef Medline

Marfurt CF, Rajchert DM (1991) Trigeminal primary afferent projections to "non-trigeminal" areas of the rat central nervous system. J Comp Neurol 303:489-511. CrossRef Medline

McKemy DD, Neuhausser WM, Julius D (2002) Identification of a cold receptor reveals a general role for TRP channels in thermosensation. Nature 416:52-58. CrossRef Medline

Morin C, Bushnell MC (1998) Temporal and qualitative properties of cold pain and heat pain: a psychophysical study. Pain 74:67-73. CrossRef Medline

Ninomiya Y, Sako N, Funakoshi M (1989) Strain differences in amiloride inhibition of $\mathrm{NaCl}$ responses in mice, Mus musculus. J Comp Physiol A 166:1-5. Medline

Ogura T, Krosnowski K, Zhang L, Bekkerman M, Lin W (2010) Chemoreception regulates chemical access to mouse vomeronasal organ: role of solitary chemosensory cells. PLoS One 5:e11924. CrossRef Medline

Ohkuri T, Horio N, Stratford JM, Finger TE, Ninomiya Y (2012) Residual chemoresponsiveness to acids in the superior laryngeal nerve in "tasteblind" (P2X2/P2X3 double-KO) mice. Chem Senses 37:523-532. CrossRef Medline

Oka Y, Butnaru M, von Buchholtz L, Ryba NJ, Zuker CS (2013) High salt recruits aversive taste pathways. Nature 494:472-475. CrossRef Medline

Otchy TM, Wolff SB, Rhee JY, Pehlevan C, Kawai R, Kempf A, Gobes SM, Ölveczky BP (2015) Acute off-target effects of neural circuit manipulations. Nature 528:358-363. CrossRef Medline

Palmiter RD (2018) The parabrachial nucleus: CGRP neurons function as a general alarm. Trends Neurosci 41:280-293. CrossRef Medline

Pittman DW, Contreras RJ (1998) Responses of single lingual nerve fibers to thermal and chemical stimulation. Brain Res 790:224-235. CrossRef Medline

Reed DR, Knaapila A (2010) Genetics of taste and smell: poisons and pleasures. Prog Mol Biol Transl Sci 94:213-240. CrossRef Medline

Rodriguez E, Sakurai K, Xu J, Chen Y, Toda K, Zhao S, Han BX, Ryu D, Yin H, Liedtke W, Wang F (2017) A craniofacial-specific monosynaptic circuit enables heightened affective pain. Nat Neurosci 20:1734-1743. CrossRef Medline

Roman CW, Derkach VA, Palmiter RD (2016) Genetically and functionally defined NTS to PBN brain circuits mediating anorexia. Nat Commun 7:11905. CrossRef Medline

Sagné C, El Mestikawy S, Isambert MF, Hamon M, Henry JP, Giros B, Gasnier B (1997) Cloning of a functional vesicular GABA and glycine transporter by screening of genome databases. FEBS Lett 417:177-183. CrossRef Medline

Schwaber JS, Sternini C, Brecha NC, Rogers WT, Card JP (1988) Neurons containing calcitonin gene-related peptide in the parabrachial nucleus project to the central nucleus of the amygdala. J Comp Neurol 270:416426, 398-399. CrossRef Medline

Scott TR, Mark GP (1987) The taste system encodes stimulus toxicity. Brain Res 414:197-203. CrossRef Medline

Simone DA, Kajander KC (1997) Responses of cutaneous A-fiber nociceptors to noxious cold. J Neurophysiol 77:2049-2060. CrossRef Medline

Simons CT, Boucher Y, Carstens E (2003a) Suppression of central taste transmission by oral capsaicin. J Neurosci 23:978-985. CrossRef Medline

Simons CT, Boucher Y, Carstens MI, Carstens E (2003b) Lack of quinineevoked activity in rat trigeminal subnucleus caudalis. Chem Senses 28: 253-259. CrossRef Medline

Sofroniew NJ, Vlasov YA, Andrew Hires SA, Freeman J, Svoboda K (2015) Neural coding in barrel cortex during whisker-guided locomotion. Elife 4:e12559. CrossRef Medline

St John SJ, Spector AC (1998) Behavioral discrimination between quinine 
and $\mathrm{KCl}$ is dependent on input from the seventh cranial nerve: implications for the functional roles of the gustatory nerves in rats. J Neurosci 18:4353-4362. CrossRef Medline

Tabachnick B, Fidell L (2001) Using multivariate statistics, Ed 4. Boston: Allyn and Bacon.

Tizzano M, Cristofoletti M, Sbarbati A, Finger TE (2011) Expression of taste receptors in solitary chemosensory cells of rodent airways. BMC Pulm Med 11:3. CrossRef Medline

Tokita K, Boughter JD Jr (2016) Topographic organizations of tasteresponsive neurons in the parabrachial nucleus of C57BL/6J mice: an electrophysiological mapping study. Neuroscience 316:151-166. CrossRef Medline

Veit L, Nieder A (2013) Abstract rule neurons in the endbrain support intelligent behaviour in corvid songbirds. Nat Commun 4:2878. CrossRef Medline

Wang Y, Erickson RP, Simon SA (1995) Modulation of rat chorda tympani nerve activity by lingual nerve stimulation. J Neurophysiol 73:1468-1483. CrossRef Medline

Wiegert JS, Mahn M, Prigge M, Printz Y, Yizhar O (2017) Silencing neu- rons: tools, applications, and experimental constraints. Neuron 95:504529. CrossRef Medline

Wilson DM, Lemon CH (2014) Temperature systematically modifies neural activity for sweet taste. J Neurophysiol 112:1667-1677. CrossRef Medline

Wilson DM, Boughter JD Jr, Lemon CH (2012) Bitter taste stimuli induce differential neural codes in mouse brain. PLoS One 7:e41597. CrossRef Medline

Yamamoto T, Shimura T, Sakai N, Ozaki N (1994) Representation of hedonics and quality of taste stimuli in the parabrachial nucleus of the rat. Physiol Behav 56:1197-1202. CrossRef Medline

Yarmolinsky DA, Peng Y, Pogorzala LA, Rutlin M, Hoon MA, Zuker CS (2016) Coding and plasticity in the mammalian thermosensory system. Neuron 92:1079-1092. CrossRef Medline

Zhao S, Ting JT, Atallah HE, Qiu L, Tan J, Gloss B, Augustine GJ, Deisseroth K, Luo M, Graybiel AM, Feng G (2011) Cell type-specific channelrhodopsin-2 transgenic mice for optogenetic dissection of neural circuitry function. Nat Methods 8:745-752. CrossRef Medline

Zotterman Y (1936) Specific action potentials in the lingual nerve of cat. Skand Arch Physiol 75:105-119. CrossRef 